DOI: $10.1002 /(($ please add manuscript number $))$

Article type: Communication

\title{
Water Transport through Ultrathin Polyamide Nanofilms Used for Reverse Osmosis
}

Zhiwei Jiang, Santanu Karan, Andrew G. Livingston*

Dr. Zhiwei Jiang, Dr. Santanu Karan, Prof. Andrew G. Livingston, Barrer Center, Department of Chemical Engineering, Imperial College London, South Kensington Campus, Exhibition Road, London SW7 2AZ, United Kingdom. E-mail: a.livingston@imperial.ac.uk.

Dr. Santanu Karan, Reverse Osmosis Division, CSIR-Central Salt and Marine Chemicals Research Institute, GB Marg, Bhavnagar - 364002, Gujarat, India.

Keywords: (ultrathin nanofilms, composite membranes, reverse osmosis, interfacial polymerization, desalination)

Thin film composite membranes comprising a polyamide nanofilm separating layer on a support material are state-of-the-art for desalination by reverse osmosis. Nanofilm thickness is thought to determine the rate of water transport through the membranes; although due to the fast and relatively uncontrolled interfacial polymerization reaction employed to form these nanofilms, they are typically crumpled and the separating layer is reported to be $\sim 50$ $200 \mathrm{~nm}$ thick. This crumpled structure has confounded exploration of the independent effects of thickness, permeation mechanism, and the support material. Herein, smooth sub-8 nm polyamide nanofilms are fabricated at a free aqueous-organic interface, exhibiting chemical homogeneity at both aqueous and organic facing surfaces. Transfer of these ultrathin nanofilms onto porous supports provides fast water transport through the resulting nanofilm composite membranes. Manipulating the intrinsic nanofilm thickness from $\sim 15$ down to $8 \mathrm{~nm}$ revealed that water permeance increases proportionally with the thickness decrease, after which it increases non-linearly to $2.7 \mathrm{~L} \cdot \mathrm{m}^{-2} \cdot \mathrm{h}^{-1} \cdot \mathrm{bar}^{-1}$ as the thickness is further reduced to $\sim 6$ nm. 


\section{WILEY-VCH}

Membrane processes for molecular separations in liquids consume less energy than conventional distillation and evaporation processes, ${ }^{[1,2]}$ but require membrane area proportional to the process volume. To reduce the area requirement, increased membrane permeance (liter per hour per sq. meter per bar; permeability / thickness) is sought, where permeability of the separating layer, as a material property, is assumed to be constant. ${ }^{[3-5]}$ Therefore, reduction of the separating layer thickness is an evident strategy for enhancing the membrane permeance by providing shorter distances for liquid transport. This approach has been applied to ultrathin diamond-like-carbon nanosheets ${ }^{[6]}$ and protein-based membranes ${ }^{[7]}$ where liquid permeances increased as separating layer thicknesses were reduced. Thin film composite membranes used for desalination by reverse osmosis (RO) are made via interfacial polymerization (IP) on a porous support, ${ }^{[1,8]}$ producing a crumpled polyamide separating layer $\sim 50$ to $200 \mathrm{~nm}$ from crest-to-trough. ${ }^{[9-11]}$ This crest-to-trough distance has typically been assumed to be the separating layer thickness. ${ }^{[3,4]}$ Due to the complex morphology of this polyamide separating layer, reducing its thickness has not yet been reported as an approach to increasing water permeance in RO membranes.

Recently, we have reported the formation of sub-10 $\mathrm{nm}$ polyamide nanofilms via controlled interfacial polymerization on a sacrificial layer, and utilized them as separating layers in nanofilm composite membranes processing organic solvents. ${ }^{[12]}$ We were able to vary the morphology of the separating layer from smooth to crumpled, where the crumpled features resulted from the folding and stacking of nanofilms and so had the same intrinsic wall thicknesses as the smooth nanofilms of ca. $8 \mathrm{~nm}$, even when the apparent thickness of the overall separating layer was ca. $100 \mathrm{~nm}$. For RO membranes, other researchers have also confirmed an intrinsic nanofilm thickness of ca. $20 \mathrm{~nm}$ where nanofilms are crumpled into a separating layer of apparent thickness $>100 \mathrm{~nm} \cdot{ }^{[13]}$ It is clear then that a key to improving RO membrane permeance is to reduce the intrinsic polyamide nanofilm thickness. In this vein, 


\section{WILEY-VCH}

more readily controllable layer-by-layer assembly has been used to make smooth polyamide nanofilms for RO ${ }^{[14]}$ However, while successful in reducing the thickness to sub-15 nm, less crosslinked nanofilms were formed, sacrificing salt $(\mathrm{NaCl})$ rejection which was below 90\%. ${ }^{[14]}$ Importantly, both sacrificial layer and layer-by-layer methods are complex, requiring additional layers for the polymerization reaction. ${ }^{[12,14]}$ What is needed is a way of reducing the intrinsic thickness of highly crosslinked polyamide nanofilms via a simple fabrication process, enabling the enhancement of water permeance and deepening the understanding of permeation mechanisms. Herein we report the fabrication of smooth sub-15 nm polyamide nanofilms with controllable thickness by interfacial polymerization at a free aqueous-organic interface (IP@FI), without the use of the complex sacrificial layer procedure we reported earlier. ${ }^{[12]}$ These free-standing and highly crosslinked nanofilms are transferred onto a variety of porous supports to provide high permeance nanofilm composite membranes for desalination.

Figure 1a shows the fabrication of polyamide nanofilms at a free interface (FI) between an aqueous phase containing $m$-phenylenediamine (MPD), and a hexane phase containing trimesoyl chloride (TMC). The nanofilm was picked from the interface and floated onto a water surface to remove residual MPD and terminate the reaction (Figure $1 \mathrm{~b}$ and Figure S1, Supporting Information). Nanofilms were then attached onto different polymeric supports and utilized as nanofilm composite membranes, or attached to other substrates for characterization (Figure S2, Supporting Information). 


\section{WILEY-VCH}

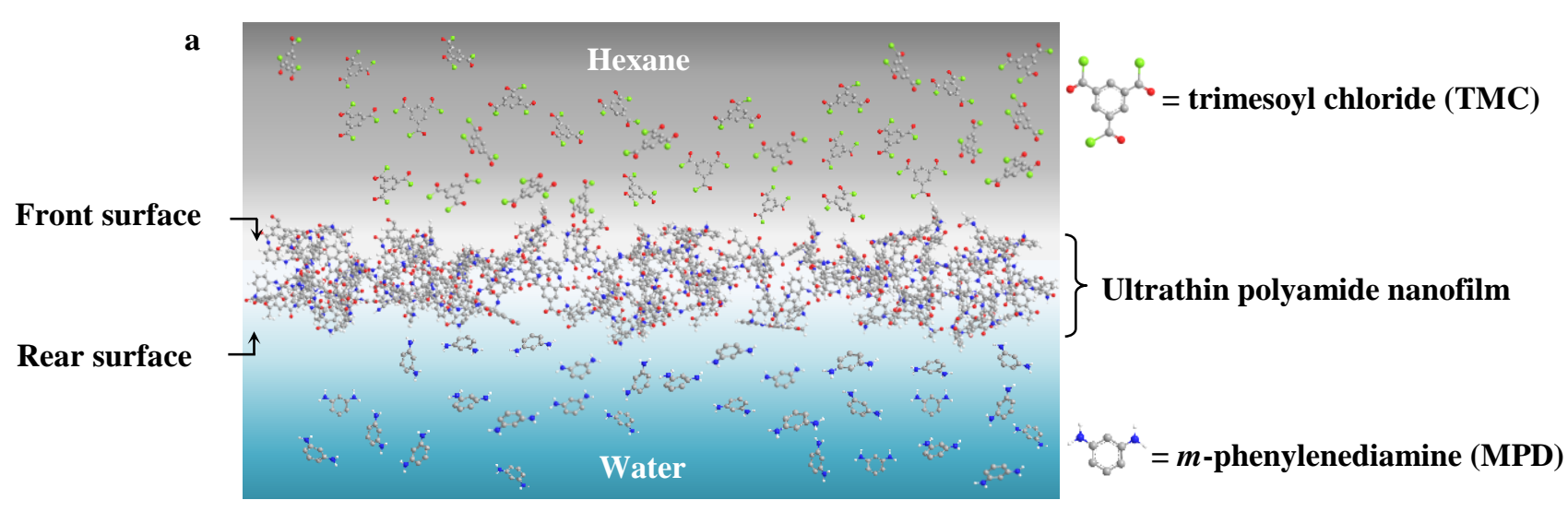

b

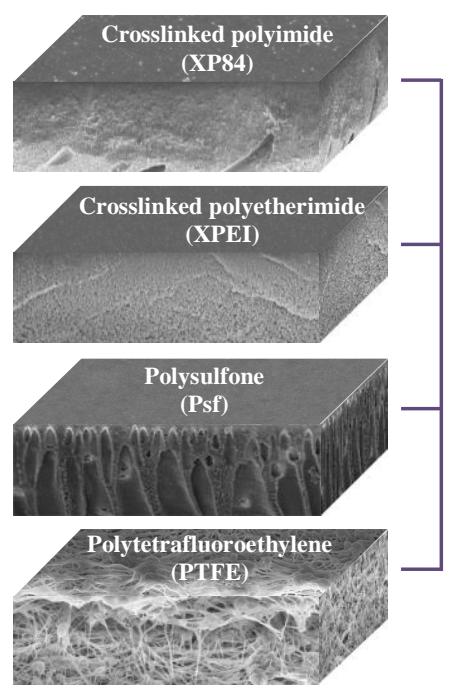

Support membranes

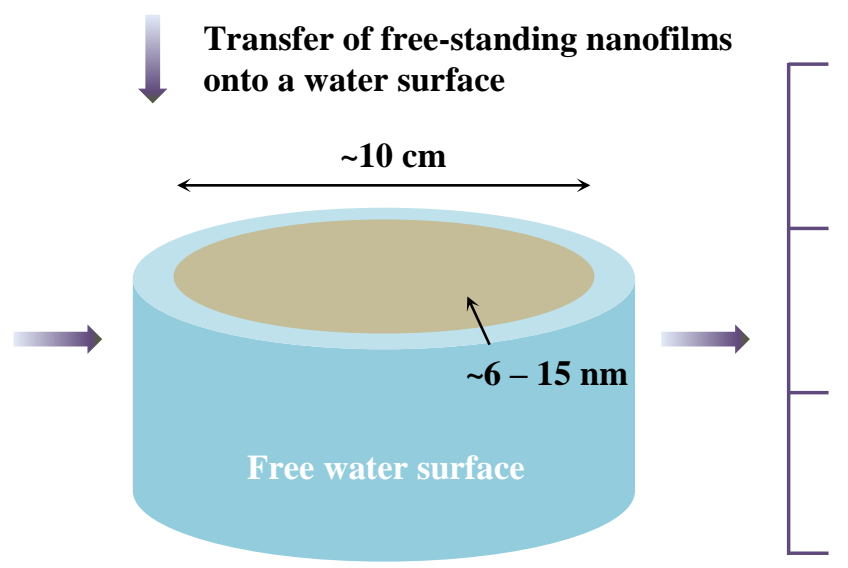

Transfer of nanofilms onto different supports

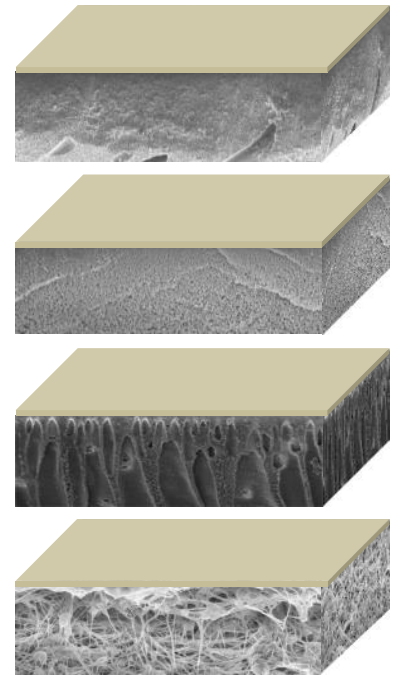

Nanofilm composite membranes

Figure 1. Schematic of the interfacial polymerization process at a free aqueous-organic interface (IP@FI) and the subsequent fabrication of nanofilm composite membranes. a) Fabrication of an ultrathin polyamide nanofilm at a free aqueous-organic interface between an aqueous phase containing $m$-phenylenediamine (MPD) and a hexane phase containing trimesoyl chloride (TMC). The front surface faces the hexane phase and the rear surface faces the aqueous phase. The growth of the nanofilm was terminated by picking it up from the interface with a polycarbonate substrate pre-submerged in the aqueous phase, and re-floating it onto a fresh water surface. b) Nanofilm composite membranes were fabricated by reattaching the polyamide nanofilms on various support membranes including crosslinked polyimide (XP84), crosslinked polyetherimide (XPEI), polysulfone (Psf), and hydrophilic polytetrafluoroethylene (PTFE). 


\section{WILEY-VCH}

a

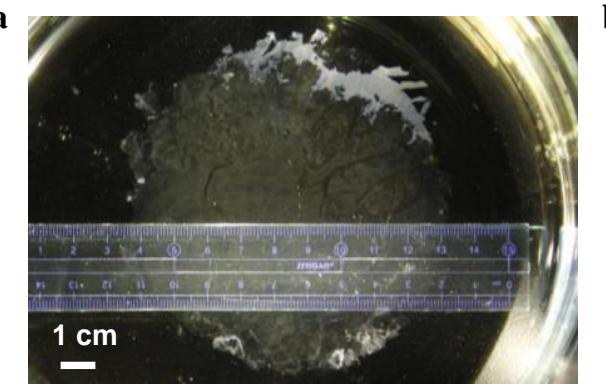

d

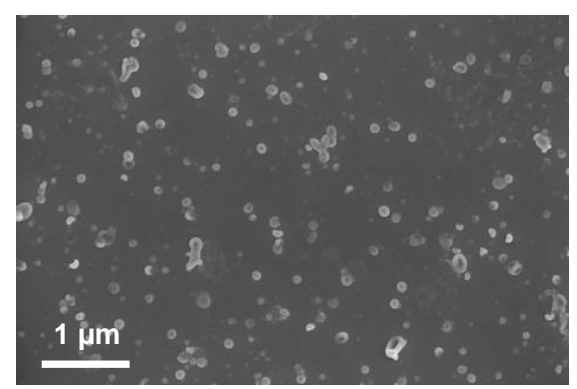

g

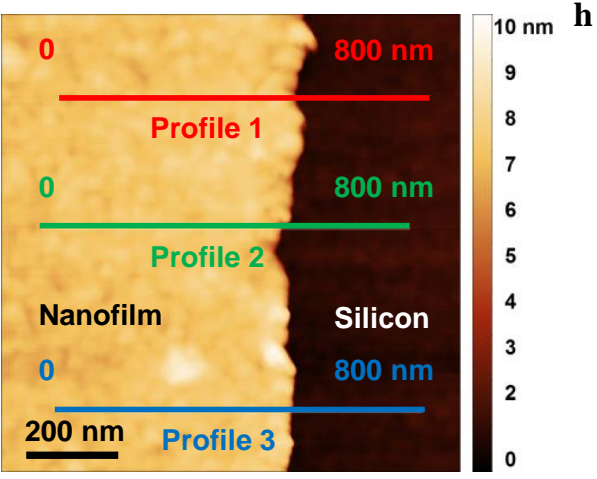

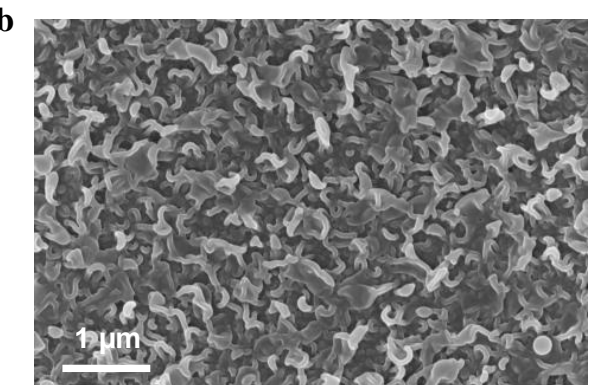
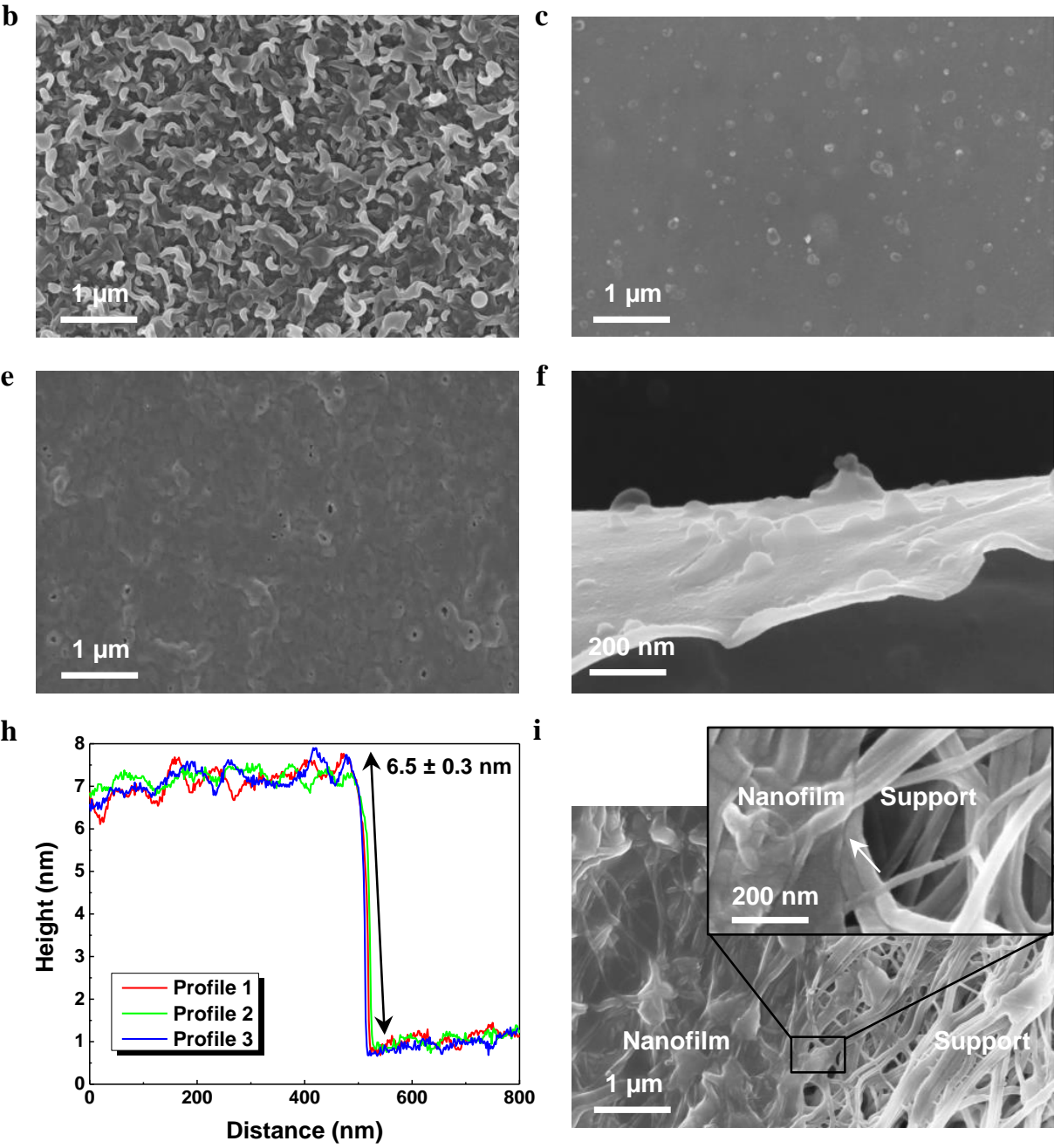

Figure 2. Optical and microscopic images of polyamide nanofilms fabricated at the free aqueous-organic interface. a) Photographic image of a $\sim 10 \mathrm{~nm}$ thick nanofilm covering a diameter of $\sim 10 \mathrm{~cm}$ transferred from the interface and re-floated on a water surface where a ruler was immersed in the water underneath the nanofilm. b) SEM image of a polyamide thin film composite membrane fabricated using a polysulfone support via conventional interfacial polymerization at a supported interface using $2 \mathrm{wt} \%$ MPD and $0.1 \mathrm{wt} \%$ TMC reacted for 1 min (IP-2\%-0.1\%-Psf). c) SEM image of a polyamide nanofilm fabricated with identical conditions as for $\mathrm{b}$ at a free interface (IP@FI-2\%-0.1\%) and then transferred onto a polysulfone support. The effect of the two modes of interfacial polymerization on the resulting surface morphology of the nanofilms is clear in the contrast between b and c. d) and e) SEM images of the front surface (facing the hexane phase) and the rear surface (facing the aqueous phase) of the nanofilm made from $3 \mathrm{wt} \%$ MPD and $0.15 \mathrm{wt} \%$ TMC reacted for 1 min (IP@FI-3\%-0.15\%), and transferred onto polysulfone supports. f) SEM cross-sectional image of a free-standing nanofilm (IP@FI-3\%-0.15\%) with nodular features as observed on the surface d. g) and h) AFM height image and profile of a free-standing nanofilm transferred onto a silicon wafer. The nanofilm was prepared from $0.05 \mathrm{wt} \%$ MPD and $0.025 \mathrm{wt} \% \mathrm{TMC}$ reacted for $1 \mathrm{~min}$ at a free interface (IP@FI-0.05\%-0.025\%). A scratch was made to expose the silicon wafer surface for the measurement of nanofilm thickness. i) SEM images of a free- 


\section{WILEY-VCH}

standing nanofilm (IP@FI-0.05\%-0.025\%) transferred onto a PTFE support. Inset shows an image at a higher magnification, for which the arrow indicates the edge of the nanofilm.

Figure 2a shows a nanofilm $\sim 10 \mathrm{~nm}$ in thickness and $\sim 10 \mathrm{~cm}$ in diameter floating on a water surface, appearing intact and defect free. The IP@FI process created smooth nanofilms ${ }^{[15,16]}$ with root-mean-square (RMS) roughness ca. one-tenth that of crumpled nanofilms prepared via conventional IP on polysulfone supports or via controlled IP on a sacrificial layer (Table S1 and Figure S3, Supporting Information), ${ }^{[12]}$ using the same reactant concentrations. We attribute the morphology difference between crumpled (Figure 2b, Figure S3, Supporting Information) and smooth (Figure 2c) nanofilms to differences in the rate of dissipation of the heat of reaction between supported and free interfaces. A free aqueous solution enables more rapid heat dissipation than an aqueous solution trapped in an ultrafiltration support or a sacrificial layer, resulting in a stable interface and the creation of smooth nanofilms at higher reactant concentrations than are possible in supported systems (Figure S4, Supporting Information). At sufficiently high monomer concentrations, nanofilms formed at the free aqueous-organic interface also underwent a transition from smooth to crumpled (Figure S5, Supporting Information), ${ }^{[1]}$ due to faster reaction kinetics accompanied by more rapid heat

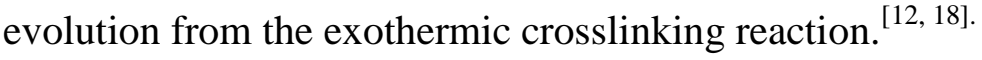

Nanofilms from the free aqueous-organic interface can be used directly, or flipped and adhered to the support so that the rear surface becomes the active surface of the membrane. Figure $2 \mathrm{~d}$ and e show scanning electron microscope (SEM) images of the front (organic facing) and rear (aqueous facing) surfaces of nanofilms fabricated via interfacial polymerization at the free aqueous-organic interface with $3 \mathrm{wt} \%$ MPD and $0.15 \mathrm{wt} \%$ TMC reacted for $1 \mathrm{~min}$ (IP@FI-3\%-0.15\%). The visible pores on the rear surface in Figure 2e reveal that the nodules observed on the front surface are hollow in nature, and that the nanofilm is a continuous sheet (Figure $2 \mathrm{f}$, Figure S6, Supporting Information). Figure $2 \mathrm{~g}$ 


\section{WILEY-VCH}

shows nanofilms (IP@FI-0.05\%-0.025\%) transferred onto a silicon wafer. A scratch was made to expose the wafer surface, from which the height profile from atomic force microscopy (AFM) gives a nanofilm thickness of $6.5 \pm 0.3 \mathrm{~nm}$ (Figure 2h). Surprisingly, this ultrathin nanofilm was mechanically robust, exhibiting a Young's modulus of $3.57 \pm 0.60$ GPa (Figure S7, Supporting Information). The nanofilm was sufficiently flexible to be transferred onto a highly porous and hydrophilic polytetrafluoroethylene (PTFE) support, without breaking or tearing apart (Figure 2i). In contrast, polyarylate nanofilms fabricated using a similar approach have shown defects and fragmented when thickness was reduced to ca. $20 \mathrm{~nm} .{ }^{[19]}$

Free-standing nanofilms were transferred onto gold $(\mathrm{Au})$ coated silicon wafers for X-ray photoelectron spectroscopy (XPS) analysis. For the nanofilms ca.10 nm thick or less, an $\mathrm{Au}$ peak was detected from the substrate as observed in the survey spectra (Figure 3a). Figure $3 b$ shows that the thickness of the nanofilms increased and the Au concentration decreased with increasing concentration of MPD (Figures S8 and S9, Supporting Information). Deconvolution of the $\mathrm{C} 1 \mathrm{~s}$ narrow scan spectrum confirms the presence of amide and carboxyl groups. For ca. $15 \mathrm{~nm}$ thick nanofilm (IP@FI-3\%-0.15\%), the percentage of carboxyl groups $(-\mathrm{COOH})$ was ca. 3.8\% when scanned from the front surface (Figure 3c), higher than the ca. 2.6\% obtained from the rear surface (Figure 3d). Further analysis of the N1s spectrum suggests that the rear surface has more free amine groups (ca. 8.5\%) than the front surface (ca. 3.8\%) (Figure S10, Supporting Information). Considering the ca. 8-10 nm penetration depth of X-rays, the interior of the nanofilm appears to be chemically homogeneous with an amine rich region a few nm thick on the rear surface, and a carboxyl rich region a few $\mathrm{nm}$ thick on the front surface. This result agrees with zeta potential measurements (Figure 3e), which show negative charge due to free carboxyl groups on both surfaces at pH above 4.2. 
a

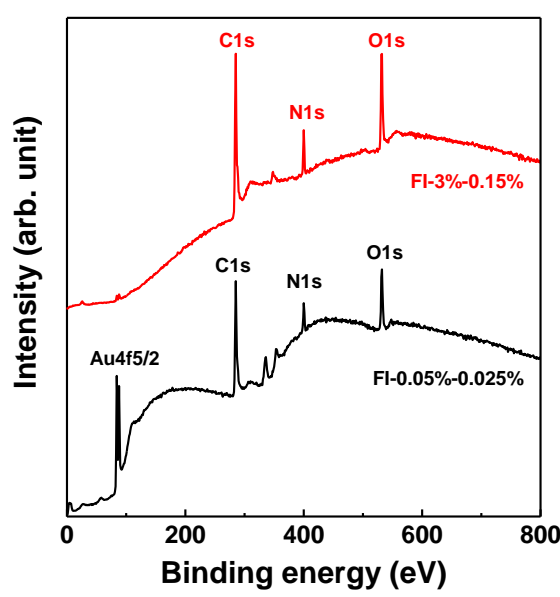

d

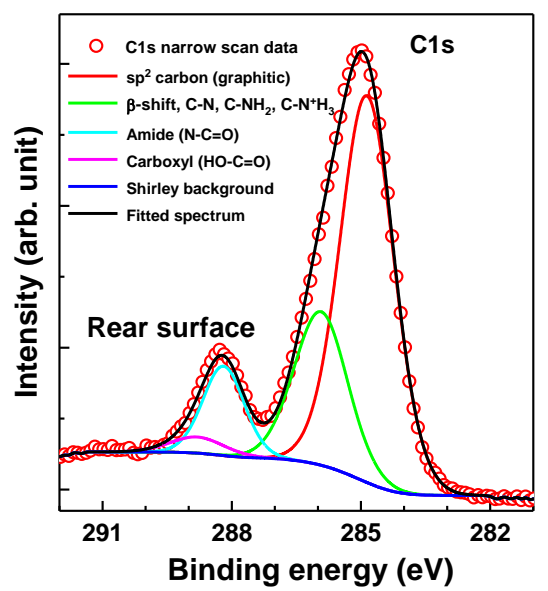

b

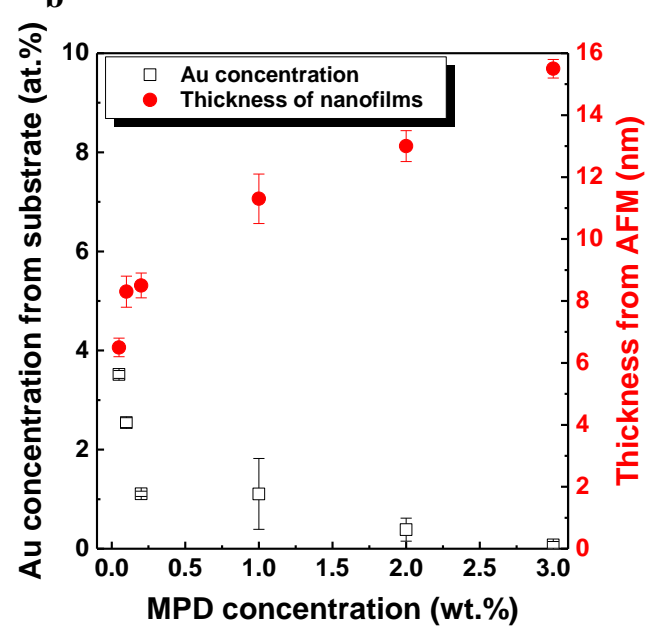

e

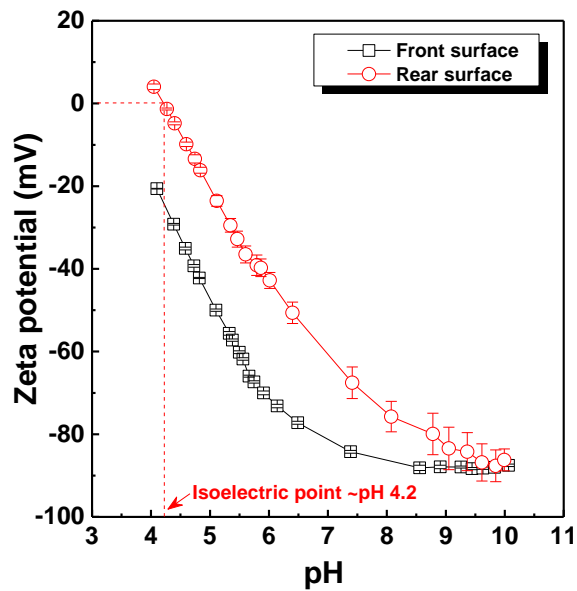

c

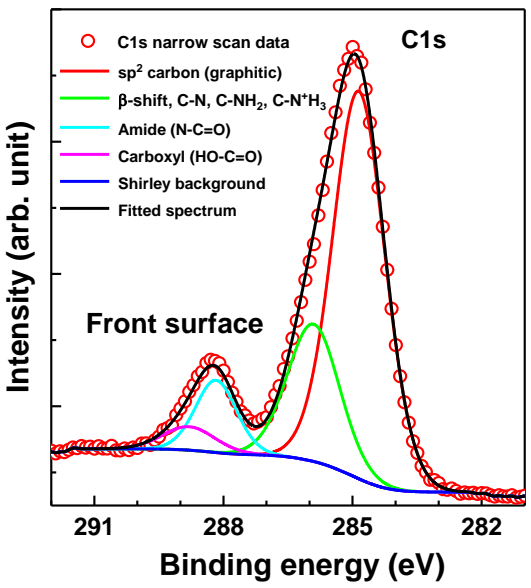

$\mathbf{f}$

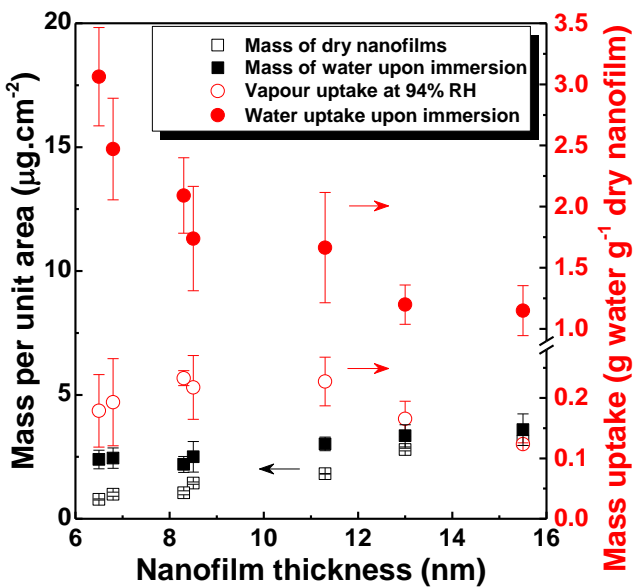

Figure 3. Properties of free-standing polyamide nanofilms fabricated at a free aqueousorganic interface. a) XPS survey spectra of the nanofilms under two different concentrations of MPD and TMC. Free-standing nanofilms were transferred onto gold ( $\mathrm{Au}$ ) coated silicon wafers. b) Plot of (i) the Au concentrations (at.\%) detected from the substrate as measured with XPS and (ii) nanofilm thickness as measured from AFM height profiles with varying MPD concentration in the interfacial polymerization reaction. c) and d) XPS narrow scan spectra of $\mathrm{C} 1 \mathrm{~s}$ measured from the front and rear surfaces of the nanofilms and the deconvoluted spectra for the probable chemical species. Nanofilms were prepared with 3 wt $\%$ MPD and $0.15 \mathrm{wt} \%$ TMC reacted for 1 min (IP@FI-3\%-0.15\%). e) Zeta potential curves for the front and rear surfaces of the nanofilm (IP@FI-3\%-0.15\%). f) Variation of mass per unit area of the nanofilms measured with a quartz crystal microbalance under dry, 94\% relative humidity $(\mathrm{RH})$, and immersion (in water) environments with increasing nanofilm thickness. The mass uptake ( $\mathrm{g}$ water $\mathrm{g}^{-1}$ dry nanofilm) was calculated from the increase in mass under saturated water vapour $(94 \% \mathrm{RH})$ conditions or increase in mass upon immersion into water. 


\section{WILEY-VCH}

As shown in Figure 3e, the lower negative value of the zeta potential on the rear surface compared to the front surface is attributed to greater density of free amine groups on the rear surface, while the net charge on both the surfaces is negative. The co-existence of free amine and carboxyl groups on both surfaces of the nanofilm is in contrast previous reports of chemical heterogeneity of commercial RO membranes. ${ }^{[20]}$ This is perhaps because the support and polyamide layer of commercial membranes interfere with each other and cannot not be individually determined. ${ }^{[10,20]}$ Figure $3 f$ shows the mass per unit superficial area of free-standing nanofilms under dry, 94\% relative humidity (RH), and fully hydrated conditions as measured by quartz crystal microbalance (QCM). The mass of dry nanofilm increased proportionally with nanofilm thickness. Under a 94\% RH environment, uptake of water vapour in the nanofilms was $\sim 0.12-0.22 \mathrm{~g}$ of water per $\mathrm{g}$ of dry nanofilm. Upon full immersion in water, the water uptake increased from $\sim 1.2$ to $3.1 \mathrm{~g}$ of water per $\mathrm{g}$ of dry nanofilm, as nanofilm thickness decreased from 15.5 to $6.5 \mathrm{~nm}$. The free volume accessible to water appears significantly higher for the sub-8 nm nanofilms.

Nanofilm composite membrane performances were evaluated for brackish water feed (2 g.L $\mathrm{L}^{-1}$ $\mathrm{NaCl}$ ) in a crossflow testing rig (Figure S11, Supporting Information). Due to the coexistence of free amine and carboxyl groups on both surfaces, nanofilms with either surface facing the feed exhibited comparable water permeances and salt $(\mathrm{NaCl})$ rejections (Figure 4a, Table S2, Supporting Information). With the rear surface as the active surface, nanofilm composite membranes exhibited $\sim 95 \% \mathrm{NaCl}$ rejection, demonstrating that the visible pores in Figure 2e are not defects but hollow features underneath the nodular separating layer (facing top). 

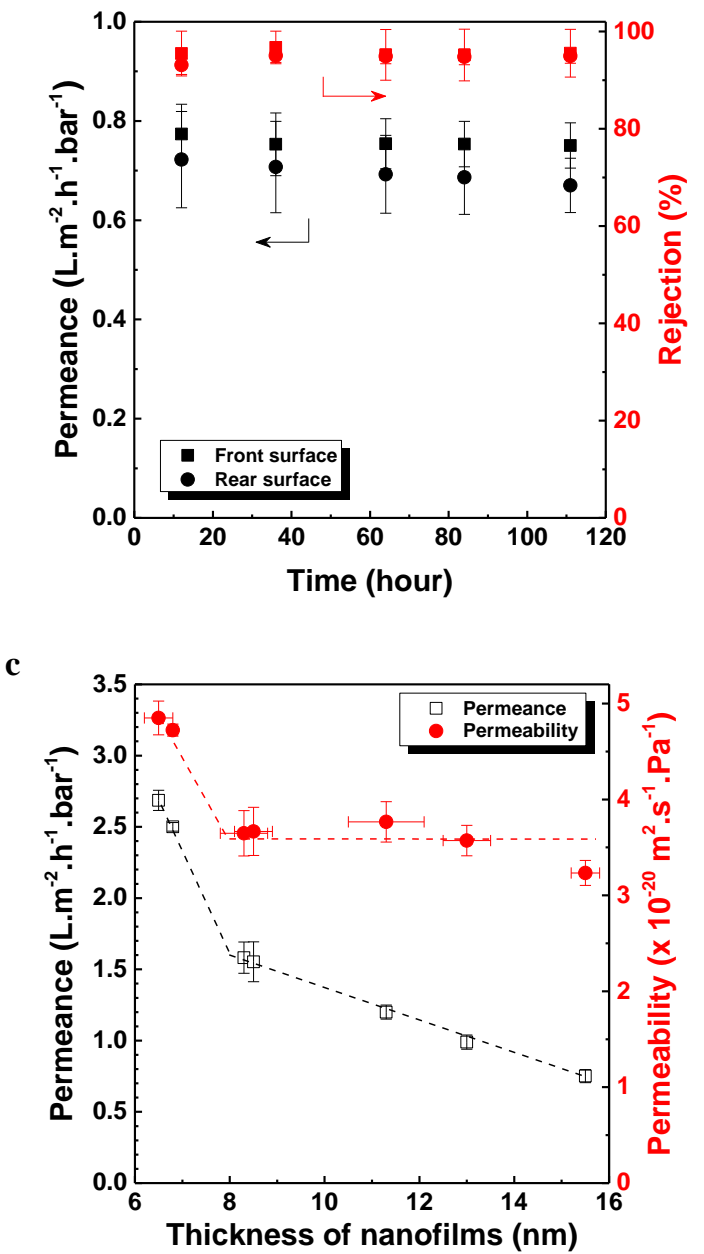

b

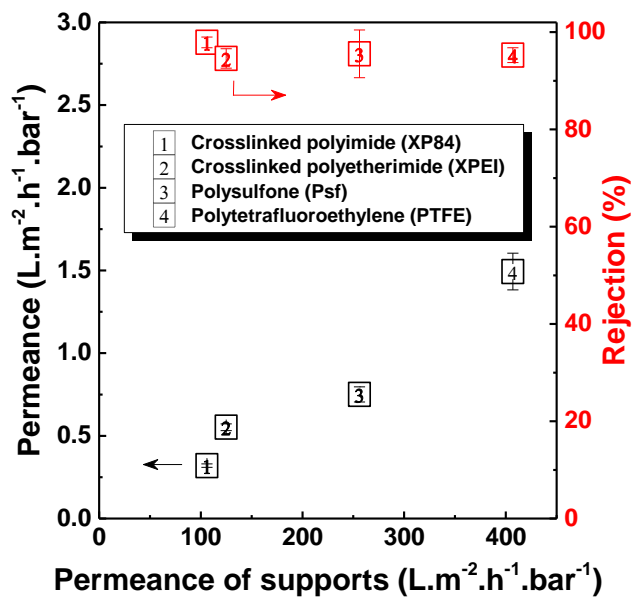

Figure 4. Reverse osmosis desalination performance of nanofilm composite membranes. a) Variation of permeance and salt $(\mathrm{NaCl})$ rejection over time for nanofilm composite membranes. Nanofilms were prepared with $3 \mathrm{wt} \%$ MPD and $0.15 \mathrm{wt} \%$ TMC reacted for 1 $\min$ at the free aqueous-organic interface (IP@FI-3\%-0.15\%) and then attached onto a polysulfone support with either front or rear surfaces facing the feed $(\mathrm{NaCl})$ solution. b) Plot of the water permeance and salt $(\mathrm{NaCl})$ rejection of nanofilm composite membranes versus the pure water permeance of support membranes. All nanofilms (IP@FI-3\%-0.15\%) were fabricated under identical conditions and subsequently transferred onto different supports. c) Variation of water permeance and permeability of nanofilm composite membranes attached onto a polysulfone support versus the nanofilm thickness. All reverse osmosis experiments were conducted in a crossflow rig at $30{ }^{\circ} \mathrm{C}$ and $100 \mathrm{~L} \cdot \mathrm{h}^{-1}$ crossflow velocity (two parallel rows of membrane cells at $50{\mathrm{~L} . \mathrm{h}^{-1}}^{-1}$ ) under 20 bar with $2 \mathrm{~g} . \mathrm{L}^{-1} \mathrm{NaCl}$ feed solution. The error bars represent the standard deviation calculated from the performance measurement of at least three independent samples. L. $\mathrm{m}^{-2} \cdot \mathrm{h}^{-1} \cdot \mathrm{bar}^{-1}$ stands for liter per square meter per hour per bar. 
Free-standing nanofilms fabricated under identical conditions (IP@FI-3\%-0.15\%) were transferred onto different supports including crosslinked polyimide (XP84), crosslinked polyetherimide (XPEI), polysulfone (Psf), and commercial hydrophilic PTFE (Figure S12, Supporting Information). Pristine supports exhibited pure water permeances at least two orders of magnitude higher than the nanofilm composite membranes (Table S3, Supporting Information). The usual assumption of the resistances-in-series model is that support resistance is negligible, ${ }^{[21]}$ implying that composite membranes with identical nanofilms should have constant permeance regardless of the supports employed. Surprisingly, for our nanofilm composite membranes we observed an increase of water permeance by more than 4 times as we employed increasingly higher permeance supports (Figure 4b). Since the nanofilms were fabricated under identical conditions, independently of the support, this cannot be attributed to the effects of the support on nanofilm formation. ${ }^{[22]}$ Rather, this experimental evidence suggests that the lateral distance that water molecules travel in the nanofilms, and in the interlayer between the nanofilms and the supports, is significant in determining the water transport rate (Figure S13, Supporting Information). Higher permeance supports, with higher surface porosity or effective surface pore density, present shorter lateral distances for water molecules to travel before encountering a pore and result in a higher flux. This effect has been predicted theoretically in previous work, and this new experimental evidence supports these predictions. ${ }^{[23,24]}$

Figure $4 \mathrm{c}$ shows permeance and permeability of water for smooth polyamide nanofilms transferred onto polysulfone supports as a function of nanofilm thickness. All nanofilms provided similar effective permeable area (Table S1, Supporting Information) and negatively charged surfaces (Figure S14, Supporting Information). Hence, any variation in permeance can be attributed to the change in nanofilm thickness. As shown in Figure 4c, the permeance increases as thickness reduces from $\sim 15.5$ to $8 \mathrm{~nm}$ in a linear fashion, after which further 


\section{WILEY-VCH}

reduction in thickness results in a non-linear increase in permeance. Composite membranes comprising $\sim 6.5 \mathrm{~nm}$ thick nanofilms on polysulfone supports (IP@FI-0.05\%-0.025\%) were robust during crossflow filtration, maintaining performance at increasing tangential velocity and applied pressure up to 40 bar (Figure S15, Supporting Information). These membranes exhibited a permeance of $2.69 \pm 0.07 \mathrm{~L} \cdot \mathrm{m}^{-2} \cdot \mathrm{h}^{-1} \cdot \mathrm{bar}^{-1}$ and $\mathrm{NaCl}$ rejection of $96.0 \pm 1.9 \%$. This is within the range of performance reported for commercial membranes tested by other researchers under similar laboratory conditions, and with our own data for a selection of commercial membranes (Figure S16, Table S4 Supporting Information). Interestingly, it is known that commercial RO membranes have a crumpled morphology, ${ }^{[9,10,13]}$ and that the area over which liquid permeation occurs in crumpled morphologies is greater than the superficial area of the membrane. ${ }^{[12]}$ This suggests that the smooth polyamide nanofilms in this work, for which the permeation and superficial membrane areas are the same, have higher permeance than the commercial membranes when compared in terms of the actual permeation area, rather than superficial membrane area; or put another way, it is consistent with the intrinsic thickness of the crumpled films in the commercial membranes being somewhat higher than the thickness of the nanofilms in this work. Indeed Yan et al. estimate that the intrinsic thickness of commercial Hydranautics ESPA2 and DOW Filmtec ${ }^{\mathrm{TM}}$ BW30 membranes is around $20 \mathrm{~nm} .{ }^{[13]}$ This work is a first, fundamental study and the techniques employed are not yet available for commercial manufacture - the resulting membranes are equivalent in performance, but not markedly better than, existing commercial materials. However, the ability to produce polymer films independently of the support opens new potential for further developments, which may ultimately lead to significantly improved membranes.

The non-linear increase in liquid permeability for the ultrathin films does not have a precedent. The usual assumption is that the permeability is a material property and is independent of the film thickness. ${ }^{[5]}$ For the linear polymer PIM-1, the hexane permeability 


\section{WILEY-VCH}

was constant for thin films with thicknesses down to $\sim 150 \mathrm{~nm}$, and decreased for sub-150 nm thick films due to increased polymer relaxation and effective packing. ${ }^{[25]}$ In contrast, the water permeability of these highly crosslinked polyamide nanofilms was unaltered down to a thickness of $\sim 8 \mathrm{~nm}$, and then increased by $\sim 40 \%$ for $\sim 6.5 \mathrm{~nm}$ nanofilms (Figure $4 \mathrm{c}$ ). This is attributed to the dramatic increase in the water uptake of sub-8 nm nanofilms which provides greater free volume than is available within thicker nanofilms (Figure 3f). Moreover, the presence of carboxyl and amine groups throughout the nanofilms (Figure $3 \mathrm{c}$ and $\mathrm{d}$ ) may facilitate fast water transport, whilst the relative contribution of surface charge (Figure S14, Supporting Information) becomes more pronounced as the nanofilm thickness is reduced to the nanometer scale. Further the tortuosity (usually $\geq 1$ ) approaches unity for ultrathin films, since the film thickness approaches the permeant dimensions $(6 \mathrm{~nm}$ is equivalent to about 25 water molecule diameters). These sub- $8 \mathrm{~nm}$ nanofilms transferred onto the $\sim 200 \mathrm{~nm}$ pore size PTFE supports (IP@FI-0.05\%-0.025\%-PTFE) were sufficiently rigid to withstand pressurization at $20 \mathrm{bar}$, and exhibited a water permeance of $4.06 \pm 0.18 \mathrm{~L} \cdot \mathrm{m}^{-2} \cdot \mathrm{h}^{-1} \cdot \mathrm{bar}^{-1}$ with $\mathrm{NaCl}$ rejection of $93.3 \pm 0.8 \%$ (Table $\mathrm{S} 2$, Supporting Information).

We report smooth polyamide nanofilms fabricated at a free aqueous-organic interface and used to form nanofilm composite membranes for desalination. This approach enables the control of nanofilm thickness from $\sim 6$ to $15 \mathrm{~nm}$, and the nanofilms exhibit a non-linear increase in permeability as the thickness reduces below $8 \mathrm{~nm}$. Supports with higher permeance offer shorter lateral distances for water molecules to travel, resulting in $>4$ times faster water transport compared to composite membranes with identical free-standing nanofilms and lower support permeance. Composite membranes comprising sub-8 nm nanofilms show similar performance to commercial membranes with crumpled surface morphologies. This study suggest that both nanofilm thickness and support permeance could 


\section{WILEY-VCH}

be engineered to create RO membranes with significantly higher permeance, and comparable rejection, to those employed in industry. 


\section{Supporting Information}

Supporting Information is available from the Wiley Online Library or from the author.

\section{Acknowledgments}

This work is supported by the BP International Centre for Advanced Materials, ROMSAF-10.

We thank M. Cook, Department of Chemical Engineering, Imperial College London, for his help in making crosslinked polyetherimide support membranes.

\section{Author contributions}

Z.W.J. and S.K. contributed equally to this work. Z.W.J., S.K., and A.G.L. designed the research. Z.W.J. performed the experiments including fabrication, characterization and reverse osmosis. S.K. analyzed XPS data and chemical compositions. Z.W.J., S.K., and A.G.L. wrote the paper.

\section{Competing financial interests}

The authors declare no competing financial interests.

\section{References}

[1] M. Elimelech, W. A. Phillip, Science 2011, 333, 712.

[2] P. Marchetti, M. F. J. Solomon, G. Szekely, A. G. Livingston, Chem. Rev. 2014, 114, 10735.

[3] E. Drazevic, K. Kosutic, V. Freger, Water Res. 2014, 49, 444.

[4] G. M. Geise, H. B. Park, A. C. Sagle, B. D. Freeman, J. E. McGrath, J. Membrane Sci. 2011, 369, 130.

[5] J. E. Lundstrom, J. Membrane Sci. 2015, 486, 138.

[6] S. Karan, S. Samitsu, X. S. Peng, K. Kurashima, I. Ichinose, Science 2012, 335, 444.

[7] X. S. Peng, J. Jin, Y. Nakamura, T. Ohno, I. Ichinose, Nat. Nanotechnol. 2009, 4, 353.

[8] J. E. Cadotte, R. J. Petersen, R. E. Larson, E. E. Erickson, Desalination 1980, 32, 25.

[9] F. Pacheco, R. Sougrat, M. Reinhard, J. O. Leckie, I. Pinnau, J. Membrane Sci. 2016, 501, 33.

[10] F. A. Pacheco, I. Pinnau, M. Reinhard, J. O. Leckie, J. Membrane Sci. 2010, 358, 51.

[11] G. Y. Chai, W. B. Krantz, J. Membrane Sci. 1994, 93, 175. 


\section{WILEY-VCH}

[12] S. Karan, Z. W. Jiang, A. G. Livingston, Science 2015, 348, 1347.

[13] H. Yan, X. P. Miao, J. Xu, G. Y. Pan, Y. Zhang, Y. T. Shi, M. Guo, Y. Q. Liu, J. Membrane Sci. 2015, 475, 504.

[14] J. E. Gu, S. Lee, C. M. Stafford, J. S. Lee, W. Choi, B. Y. Kim, K. Y. Baek, E. P. Chan, J. Y. Chung, J. Bang, J. H. Lee, Adv. Mater. 2013, 25, 4778.

[15] S. J. Park, W. Choi, S. E. Nam, S. Hong, J. S. Lee, J. H. Lee, J. Membrane Sci. 2017, $526,52$.

[16] S. J. Park, W. G. Ahn, W. Choi, S. H. Park, J. S. Lee, H. W. Jung, J. H. Lee, J Mater Chem A 2017, 5, 6648.

[17] Y. Jin, Z. H. Su, J. Membrane Sci. 2009, 330, 175.

[18] T. D. Matthews, H. Yan, D. G. Cahill, O. Coronell, B. J. Marinas, J. Membrane Sci. 2013, 429, 71.

[19] M. F. Jimenez-Solomon, Q. L. Song, K. E. Jelfs, M. Munoz-Ibanez, A. G. Livingston, Nat. Mater. 2016, 15, 760.

[20] V. Freger, Langmuir 2003, 19, 4791.

[21] D. R. Machado, D. Hasson, R. Semiat, J. Membrane Sci. 2000, 166, 63.

[22] A. K. Ghosh, E. M. V. Hoek, J. Membrane Sci. 2009, 336, 140.

[23] G. Z. Ramon, M. C. Y. Wong, E. M. V. Hoek, J. Membrane Sci. 2012, 415, 298.

[24] M. Kattula, K. Ponnuru, L. X. Zhu, W. G. Jia, H. Q. Lin, E. P. Furlani, Sci. Rep-Uk 2015, 5 .

[25] P. Gorgojo, S. Karan, H. C. Wong, M. F. Jimenez-Solomon, J. T. Cabral, A. G. Livingston, Adv. Funct. Mater. 2014, 24, 4729. 


\section{WILEY-VCH}

\section{Table of Contents}

Smooth, ultrathin polyamide nanofilms with controllable thickness from ca. 6 to $15 \mathrm{~nm}$ are fabricated at a free interface between aqueous and organic liquids and used for reverse osmosis. Transfer of these nanofilms onto various support materials enables exploration of the independent impacts of nanofilm thickness and support properties on composite membrane performance. Sub- $8 \mathrm{~nm}$ nanofilms on more porous supports exhibit fast water transport and good $\mathrm{NaCl}$ rejection.

Keywords: (ultrathin nanofilms, composite membranes, reverse osmosis, interfacial polymerization, desalination)

Zhiwei Jiang, Santanu Karan, Andrew G. Livingston*

Water Transport through Ultrathin Polyamide Nanofilms Used for Reverse Osmosis
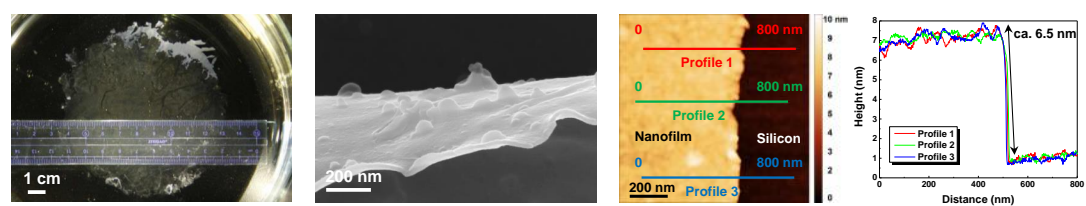
Copyright WILEY-VCH Verlag GmbH \& Co. KGaA, 69469 Weinheim, Germany, 2016. Supporting Information

Water Transport through Ultrathin Polyamide Nanofilms Used for Reverse Osmosis Zhiwei Jiang, Santanu Karan, Andrew G. Livingston*

\section{Experimental details}

\section{Chemical used}

Polyimide (PI) polymer (P84) was purchased from HP Polymer GmbH (Austria). Hydrophilic polytetrafluoroethylene (PTFE) membrane filters were purchased from Advantec Japan. Commercial membranes including Dow Filmtec ${ }^{\mathrm{TM}}$ SW30HR, TriSep ${ }^{\mathrm{TM}}$ X20, and GE Osmonics $^{\mathrm{TM}}$ AG were purchased from Sterlitech Corporation USA. Trimesoyl chloride (TMC) 98\%, m-phenylenediamine (MPD) flakes 99\%, polysulfone pellets with average molecular weight 35,000 g.mol ${ }^{-1}$, 1,6-hexanediamine (HDA) 99.5\% were purchased from Sigma Aldrich, UK. Vacuum sublimation $\left(1 \times 10^{-2}\right.$ mbar $)$ was used to purify $m$ phenylenediamine at $80^{\circ} \mathrm{C}$. Single crystal silicon wafers (phosphorous doped, (100) polished) were purchased from Si-Mat Germany and used as a substrate for atomic force microscopy (AFM) measurement. PLATYPUS ${ }^{\mathrm{TM}}$ silicon wafers with $100 \mathrm{~nm}$ thick gold coating were purchased from Agar Scientific, UK and used for X-ray photoemission spectroscopy (XPS) studies. Dimethylformamide (DMF) and n-methyl-2-pyrrolidone (NMP) used for making polymeric supports were purchased from VWR, UK.

\section{Characterization methods}

Quartz crystal microbalance (QCM) 


\section{WILEY-VCH}

The mass of the nanofilms was estimated using a quartz crystal microbalance (QCM200, Stanford Research Systems, Sunnyvale, USA). AT-cut quartz crystals with Cr/gold electrodes and a fundamental oscillating frequency of $5 \mathrm{MHz}$ (Stanford Research Systems, Inc.) were used as the probe. Measurements were taken at a 1s interval and the accuracy of the frequency counter was $0.1 \mathrm{~Hz}$. Free-standing nanofilms were transferred directly onto the quartz crystal and dried at $50^{\circ} \mathrm{C}$ for $3 \mathrm{~h}$ under vacuum, followed by continuous drying at room temperature overnight without breaking vacuum.

\section{$X$-ray photoelectron spectroscopy (XPS)}

Oxford Materials Characterization Service and BegbrokeNano, Department of Materials, Oxford University provided the X-ray photoemission spectroscopy (XPS) study. Freestanding nanofilms were floated on a water surface and transferred onto a PLATYPUS ${ }^{\mathrm{TM}}$ gold coated silicon wafer, washed in water and dried. The survey spectra and core level XPS spectra were recorded from at least three different spots on a sample with size $400 \mathrm{x} 400 \mu \mathrm{m}^{2}$. XPS was performed in an ion pumped VG Microtech CLAM 4 MCD analyser system. 250 Watt monochromatic Al Ka (1468.68 eV) excitation was used. The analyser was operated at constant pass energy of $200 \mathrm{eV}$ for wide scans and $20 \mathrm{eV}$ for detailed scans setting the $\mathrm{C} 1 \mathrm{~s}$ peak at BE $285 \mathrm{eV}$ to overcome any sample charging. Data was obtained using SPECTRA version 8 operating system. Data processing and deconvolution of narrow scan spectra were performed in CasaXps software. Peak areas were measured after satellite subtraction and background subtraction, either with a linear background or following the methods of Shirley, as reported elsewhere. ${ }^{[1]}$ The area under the principal peak of each element in the spectrum, divided by an empirically derived sensitivity factor, is proportional to the concentration of that element on the surface (for approximately the top $10 \mathrm{~nm}$ ).

\section{Scanning electron microscopy (SEM)}


The surfaces and cross-sectional scanning electron microscopic images of different nanofilms were characterized by high resolution scanning electron microscope (SEM), LEO 1525, Karl Zeiss with an accelerating voltage of $5 \mathrm{kV}$. A $5 \mathrm{~nm}$ thick (measured with attached QCM thickness monitor) coating of chromium was sputtered (Q150T turbo-pumped sputter coater, Quorum Technologies Ltd.) under an argon atmosphere $\left(2 \times 10^{-2} \mathrm{mbar}\right)$ to achieve a minimum conductivity and avoid sample charging.

\section{Atomic force microscopy $(A F M)$}

Multimode 8 (Bruker, CA, USA) atomic force microscope (AFM) equipped with E - type or $\mathbf{J}$ - type pizzo scanner was used to measure the thickness, surface roughness, and the scanned area per unit projected area (actual area per unit superficial area) of the nanofilms. Samples were attached onto a magnetic sample disk using double sided tape. The images were captured under tapping mode using PointProbe ${ }^{\circledR}$ Plus silicon-SPM probes (PPP-NCH, Nanosensors $^{\mathrm{TM}}$, Switzerland) with typical tip radius of less than $7 \mathrm{~nm}$. The cantilever resonance frequency was in the range of $204-497 \mathrm{kHz}$ with a nominal spring constant of 42 N.m ${ }^{-1}$. A sampling resolution of at least 512 points per line and a speed of $0.2-1 \mathrm{~Hz}$ were used. Gwyddion 2.44 SPM data visualization and analysis software was used to process the AFM images. Surface roughness is presented as root-mean-square roughness $\left(\mathrm{R}_{\mathrm{rms}}\right)$. Surface morphology, roughness parameters and the thickness were estimated from AFM scans on different substrates. To measure the thickness, free-standing nanofilms were transferred to silicon wafers and dried. A scratch was made to expose the wafer surface and allow measurement of the height from the silicon wafer surface to the nanofilm surface. Nanofilm thickness was estimated from the height difference between the silicon and the nanofilm using a one dimensional statistical function.

\section{Conductivity measurement}




\section{WILEY-VCH}

The conductivity of solutions was measured by the Hanna HI 8733 conductivity meter, to give concentration of dissolved $\mathrm{NaCl}$ ions in the permeate $\left(C_{p}\right)$ and feed $\left(C_{f}\right)$. At least $20 \mathrm{ml}$ solution was collected each time for the measurement. The rejection $\left(R_{j}\right)$ of the membranes was calculated from the conductivity ratio between the permeate solution $\left(\sigma_{p}\right)$ to the feed solution $\left(\sigma_{f}\right)$ and the crossflow rig was used to ensure good mixing (high mass transfer) in the process.

$R_{j}=1-\frac{C_{p}\left(\sigma_{p}\right)}{C_{f}\left(\sigma_{f}\right)}$

Equation S1

\section{Zeta potential measurement at the membrane surface}

The zeta potential of the membrane surface was measured by SurPASS zeta potential analyser from Anton Paar Ltd. A rectangular clamp cell was used to fix the membrane samples. For each test, a membrane sheet $\left(1 \times 2 \mathrm{~cm}^{2}\right)$ was cut and attached onto a holder with water-proof double-sided tape, followed by fixing the holder into the rectangular clamp cell. The system was washed with DI water prior to each test. The $\mathrm{pH}$ and conductivity were calibrated before each test. The $50 \mathrm{mM} \mathrm{HCl}$ and $\mathrm{NaOH}$ solutions were used to vary the $\mathrm{pH}$ in the system by titration from 4 to 11 , while the zeta potential of the surface was measured.

\section{Fabrication of polymeric supports via phase inversion}

Polyimide support membranes were bench cast on an Elcometer 4340 Automatic Film Applicator. Dope solution was made by dissolving $22 \mathrm{wt} \%$ polyimide powder in DMF and stirred overnight. Prior to casting, the dope solution was allowed to stand for 3 hours to remove air bubbles. The gap between the casting knife and the polypropylene non-woven backing (Novatexx 2471, Freudenberg, Germany) was set at $250 \mu \mathrm{m}$. The casting speed was fixed at $7 \mathrm{~cm} \cdot \mathrm{s}^{-1}$. Immediately after casting onto the non-woven backing, the dope/non-woven composite was immersed in a water bath to perform phase inversion. 


\section{WILEY-VCH}

Polysulfone membranes were cast using a continuous casting machine (Sepratek, South Korea). The dope solution was prepared by dissolving $17 \mathrm{wt} \%$ polysulfone pellets in NMP and stirred overnight. Prior to casting, the dope solution was allowed to stand for 3 hours to remove the air bubbles. The gap between the casting knife and the polypropylene non-woven backing was set at $150 \mu \mathrm{m}$. The casting speed was controlled by the winder tension. After casting on the non-woven backing, the dope/non-woven composite was underwent phase inversion through tangential entry into the water bath.

All support membranes were cast in a room with controlled temperature $\left(25^{\circ} \mathrm{C}\right)$ and humidity (30\%), and subsequently transferred into water and stored in a cold room at a constant temperature of $4{ }^{\circ} \mathrm{C}$.

\section{Synthesis of polyamide nanofilms at a free aqueous-organic interface}

A free aqueous-organic interface was created between an aqueous phase containing MPD and a hexane phase containing TMC in a glassware container. After 1 min reaction, nanofilms were picked-up on a substrate and rinsed with excess hexane to remove residue TMC, followed by floating them on a water surface for relaxation. The nanofilms were then transferred onto various supports to incorporate them into thin film composite membranes for desalination experiments, or onto substrates for characterization. The thickness and surface roughness of the nanofilms was controlled by tuning monomer concentrations as listed in Table S1.

\section{Desalination experiments by reverse osmosis in a crossflow rig}

All membranes were tested in a crossflow rig with 8 stainless cells (Figure S11) in two parallel rows each containing 4 cells in series. The membranes were placed on the sintered disc and sealed by the inner O-ring, and mounted in the cell (Figure S11). The flow rate was 


\section{WILEY-VCH}

provided by the liquid pump and maintained greater than $100 \mathrm{~L} \cdot \mathrm{h}^{-1}$ through two parallel rows (each row $50 \mathrm{~L} \cdot \mathrm{h}^{-1}$ ). The cell input flow (feed in) was introduced tangentially to create good mixing close to the membrane surface so as to minimise concentration polarisation. The operating conditions for all nanofilm composite membranes used $2 \mathrm{~g} . \mathrm{L}^{-1} \mathrm{NaCl}$ solution as the feed at $30{ }^{\circ} \mathrm{C}$ under 20 bar. The water permeance of nanofilm composite membranes, $P_{N F C}$, was calculated following Equation S2.

$P_{N F C}=\frac{V}{A \cdot \Delta t \cdot \Delta P}$ Equation S2

where $V$ is the volume of permeate collected (L), $A$ is the superficial area of the membrane $\left(\mathrm{m}^{2}\right), \Delta t$ is the time elapsed for collecting the required permeate volume $(\mathrm{h}), \Delta P$ is the transmembrane pressure (bar). The unit of the permeance was liter per square meter per hour per bar $\left(\mathrm{L} \cdot \mathrm{m}^{-2} \cdot \mathrm{h}^{-1} \cdot \mathrm{bar}^{-1}\right)$ which is the conventional standard. 


\section{WILEY-VCH}

a

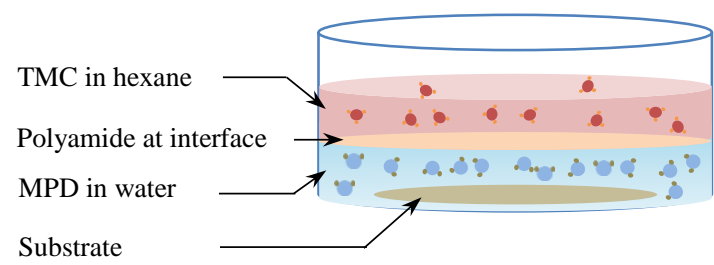

d

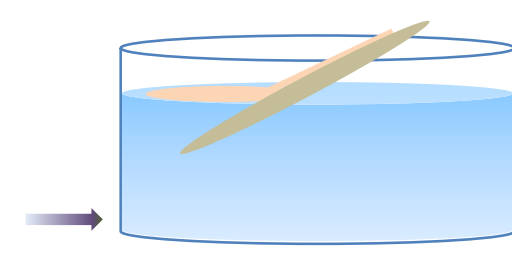

$v=\sum^{2}=m$-phenylenediamine (MPD) b

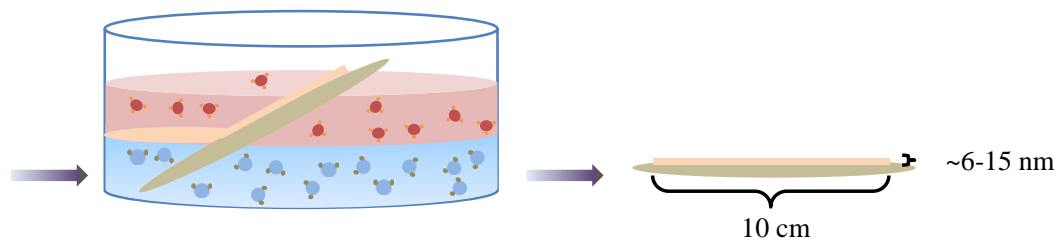

f

g

Figure S1. Schematic of free-standing polyamide nanofilms fabricated at a free interface. a) Instantaneous formation of polyamide nanofilm at the interface between an aqueous phase containing MPD and a hexane phase containing TMC. b) Free-standing polyamide nanofilms were picked-up by a substrate. c) Polyamide nanofilms with diameter $\sim 10 \mathrm{~cm}$ and thickness varying from $\sim 6$ to $15 \mathrm{~nm}$ were lifted out of the biphasic mixture. d) Nanofilms were floated off the substrate onto a water surface. e) Defect-free nanofilms were allowed to extend on the water surface. f) Nanofilms were transferred onto the supports. g) A nanofilm composite membrane with the polyamide nanofilm as the active layer on the support.

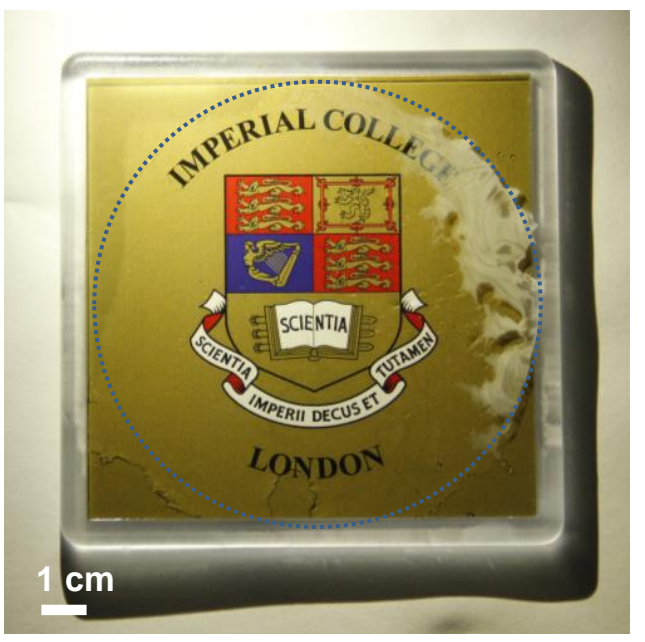

Figure S2. Photograph of a free-standing ultrathin nanofilm with $10 \mathrm{~cm}$ diameter transferred onto a substrate. 
Table S1. Properties of nanofilms fabricated at a free aqueous-organic interface.

\begin{tabular}{|c|c|c|c|c|c|c|}
\hline $\begin{array}{l}\text { Polyamide nanofilms } \\
\text { made at the free aqueous- } \\
\text { organic interface (FI)* } \\
\text { (IP@FI-MPD wt\%-TMC } \\
\text { wt\%) }\end{array}$ & $\begin{array}{l}\text { Thickness } \\
\text { from } \mathbf{A F M}^{\dagger} \\
(\mathrm{nm})\end{array}$ & $\begin{array}{l}\text { RMS } \\
\text { roughness }\end{array}$ & $\begin{array}{l}\text { Actual area per } \\
\text { superficial area } \\
(-)\end{array}$ & $\begin{array}{l}\begin{array}{l}\text { COOH } \\
\text { content }\end{array} \\
(\%)\end{array}$ & $\begin{array}{l}\text { Mass per unit } \\
\text { superficial } \\
\text { area }^{\S} \\
\left(\mu \mathrm{g} . \mathrm{cm}^{-2}\right)\end{array}$ & $\begin{array}{l}\text { Water uptake }^{\S} \\
\text { (g water } \mathrm{g}^{-1} \text { dry } \\
\text { nanofilm) }\end{array}$ \\
\hline IP@FI-0.01\%-0.005\% & $4.5 \pm 0.3$ & $0.18 \pm 0.01$ & 1.00 & ND & ND & ND \\
\hline IP@FI-0.05\%-0.025\% & $6.5 \pm 0.3$ & $0.27 \pm 0.02$ & 1.00 & $3.5 \pm 0.3$ & $0.78 \pm 0.02$ & $3.06 \pm 0.40$ \\
\hline IP@FI-0.06\%-0.03\% & $6.8 \pm 0.1$ & $0.30 \pm 0.01$ & 1.00 & ND & $0.99 \pm 0.08$ & $2.41 \pm 0.41$ \\
\hline IP@FI-0.1\%-0.05\% & $8.3 \pm 0.5$ & $1.11 \pm 0.18$ & 1.00 & $3.0 \pm 0.1$ & $1.05 \pm 0.08$ & $2.00 \pm 0.31$ \\
\hline IP@FI-0.2\%-0.1\% & $8.5 \pm 0.1$ & $1.63 \pm 0.21$ & 1.00 & $3.4 \pm 0.3$ & $1.44 \pm 0.04$ & $1.74 \pm 0.20$ \\
\hline IP@FI-1\%-0.05\% & $11.3 \pm 0.8$ & $3.70 \pm 0.41$ & 1.01 & $3.9 \pm 0.1$ & $1.82 \pm 0.02$ & $1.66 \pm 0.15$ \\
\hline IP@FI-2\%-0.1\% & $13.0 \pm 0.5$ & $5.93 \pm 0.52$ & 1.02 & $3.5 \pm 0.3$ & $2.79 \pm 0.05$ & $1.20 \pm 0.16$ \\
\hline IP@FI-3\%-0.15\% & $15.5 \pm 0.3$ & $8.48 \pm 1.11$ & 1.02 & $3.8 \pm 0.1$ & $3.13 \pm 0.23$ & $1.15 \pm 0.20$ \\
\hline
\end{tabular}

The reaction time for all nanofilms was 1 minute. "Thickness, root-mean-square (RMS) roughness and actual area per superficial area of nanofilm were measured on silicon wafers by AFM. ${ }^{\ddagger} \mathrm{COOH}$ content was estimated from the core-level C1s XPS spectra of free-standing nanofilms transferred onto gold-coated silicon wafers. ${ }^{8}$ Water uptake was the mass of water sorption per unit mass of dry nanofilms as measured by QCM.
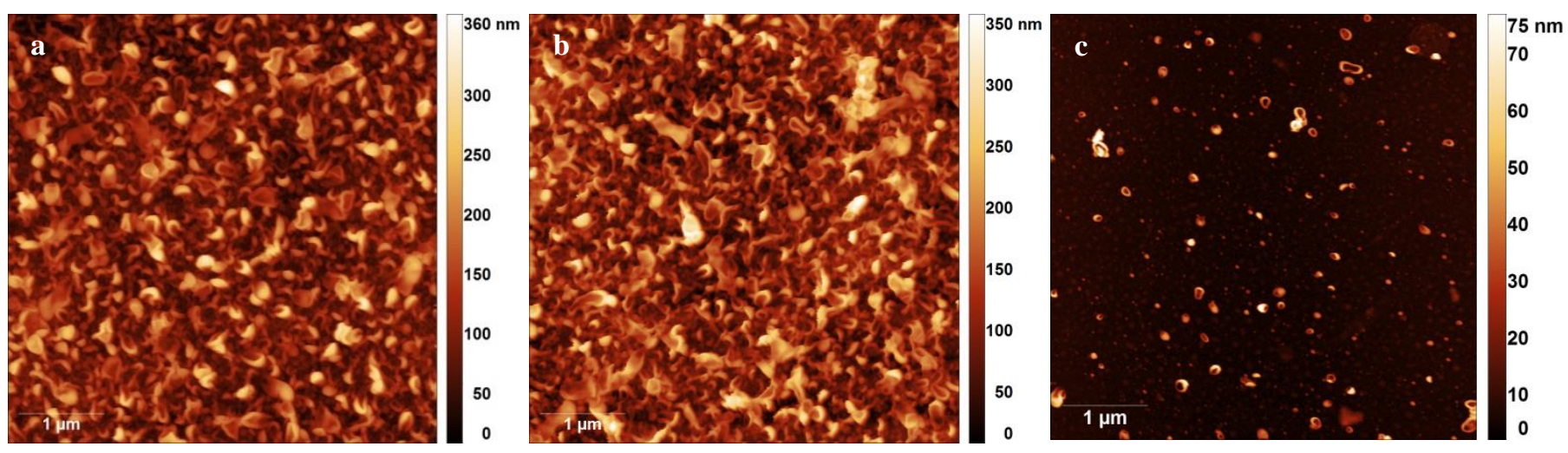

Figure S3. AFM height images of the nanofilms fabricated using different methods. a) Nanofilms made via conventional interfacial polymerization on a polysulfone support, RMS roughness $52.8 \pm 0.6 \mathrm{~nm}$. b) Nanofilms made via controlled interfacial polymerization with a sacrificial layer on a polysulfone support, RMS roughness $54.8 \pm 1.2 \mathrm{~nm}$. c) Nanofilms made at a free aqueous-organic interface, RMS roughness $5.9 \pm 0.5 \mathrm{~nm}$. All polyamide nanofilms were fabricated from same reactant concentrations of $2 \mathrm{wt} \%$ MPD and $0.1 \mathrm{wt} \%$ TMC reacted for $1 \mathrm{~min}$. 


\section{WILEY-VCH}

At the free interface, the nanofilm is formed on the bulk water surface rather than a very thin (not bulk) aqueous layer on/in a porous support (Figure S4). Polymeric supports and the sacrificial layer are poor for heat transfer, so the heat dissipates through the bulk hexane layer when interfacial polymerization is on the supports. Since water has a higher heat capacity than hexane, the local temperature rises are reduced and smoother nanofilms are created when interfacial polymerisation is takes place at the bulk liquid interface.

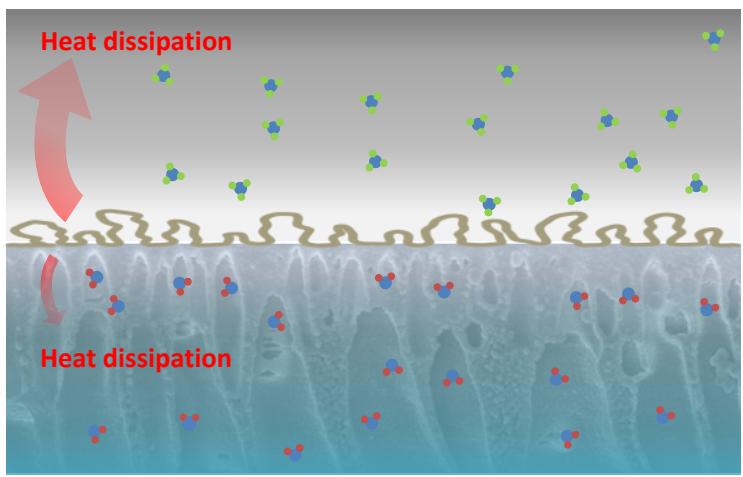

b

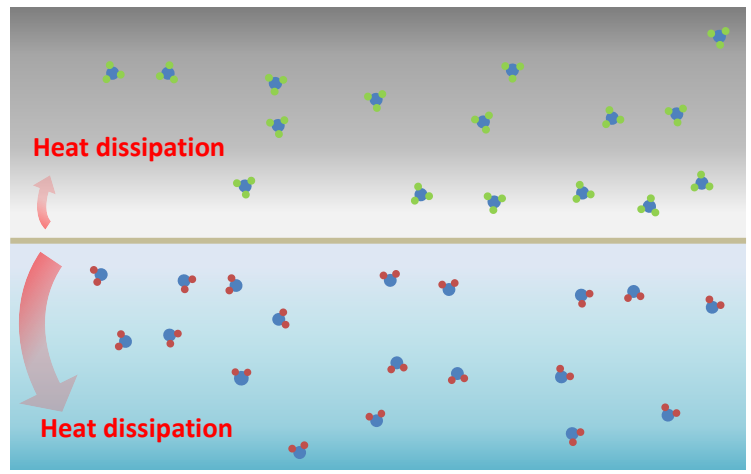

$\varphi=\sum^{2}=m$-phenylenediamine (MPD)

Figure S4. Schematic of heat dissipation pathways for nanofilms made a) on polymeric supports at a supported aqueous-organic interface and b) at a free aqueous-organic interface.
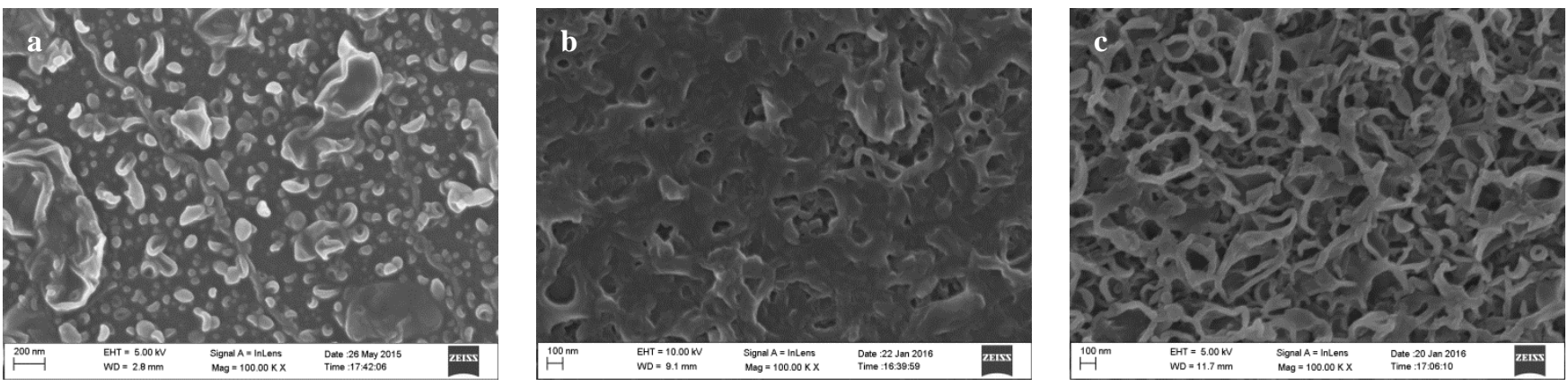

Figure S5. SEM images of nanofilms made from high monomer concentrations. a) MPD 3 wt $\%$ and TMC $1.5 \mathrm{wt} \%$, b) MPD $4 \mathrm{wt} \%$ and TMC $2 \mathrm{wt} \%$, and c) MPD $6 \mathrm{wt} \%$ and TMC 3 wt $\%$ reacted for $1 \mathrm{~min}$ at a free aqueous-organic interface and then transferred onto polysulfone supports. 


\section{WILEY-VCH}

a

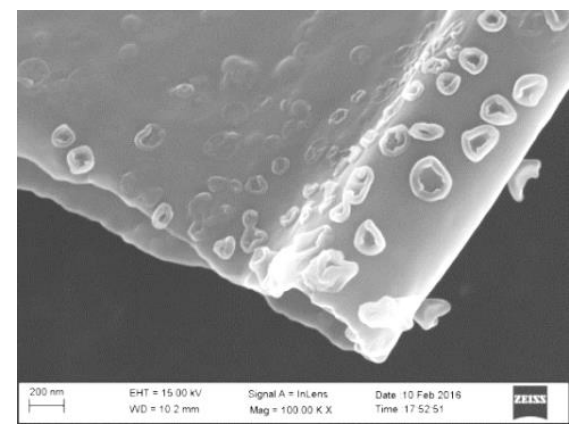

b

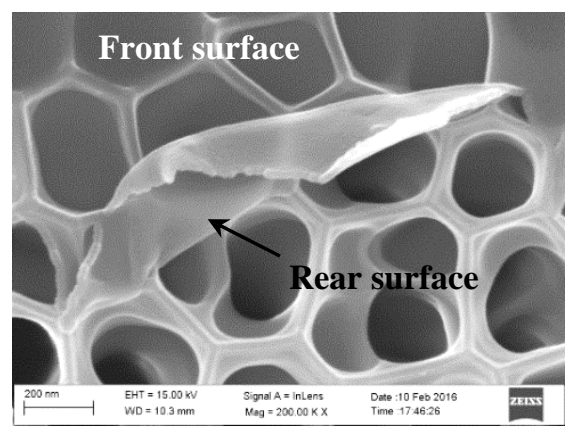

Figure S6. SEM images of buckling nanofilms made at a free aqueous-organic interface from a) MPD $3 \mathrm{wt} \%$ and TMC $0.15 \mathrm{wt} \%$ reacted for $1 \mathrm{~min}$ (IP@ FI-3\%-0.15\%) and b) MPD 0.1 $\mathrm{wt} \%$ and TMC $0.05 \mathrm{wt} \%$ reacted for $1 \mathrm{~min}$ (IP@FI-0.1\%-0.05\%).

a

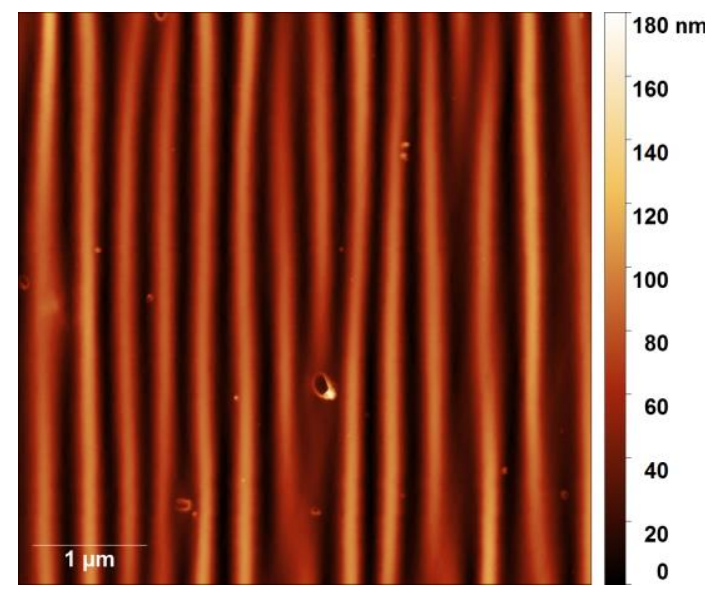

b

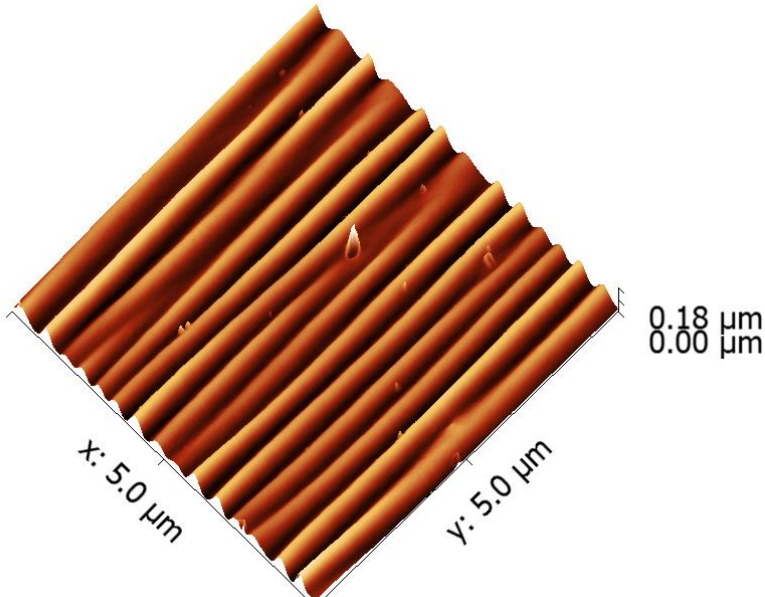

Figure S7. AFM height images of wrinkled nanofilms made at a free aqueous-organic interface from MPD $0.05 \mathrm{wt} \%$ and TMC $0.025 \mathrm{wt} \%$ reacted for $1 \mathrm{~min}$ (IP@FI-0.05\%$0.025 \%$ ) and subsequently transferred onto an elastomer. a) Top view height image and b) 3D height image.

For the ultrathin and smooth nanofilm, the elastic modulus can be measured by transferring onto a stretched PDMS elastomer. ${ }^{[1]}$ After the PDMS elastomer relaxes, the nanofilm buckles and wrinkles appear. By measuring the wavelength of wrinkles (Figure S7), the Young's modulus of the nanofilm can be calculated as:

$E_{n f}=3 E_{s} \frac{\left(1-v_{n f}^{2}\right)}{\left(1-v_{s}^{2}\right)}\left(\frac{\lambda}{2 \pi h_{n f}}\right)^{3}$ 


\section{WILEY-VCH}

where $E$ and $v$ are the elastic modulus and the Poisson's ratio, the subscripts $s$ and $n f$ denote the substrate (PDMS elastomer) and the nanofilm, and $\lambda$ is the wavelength of the wrinkles. The Young's modulus of the elastomer was $1.86 \pm 0.15 \mathrm{MPa}$, and the Posisson's ratio of elastomer and nanofilm was assumed to be 0.49 and 0.39 respectively. ${ }^{[1]}$ The wavelength of the wrinkles for the ca. $6.5 \mathrm{~nm}$ nanofilm (IP@FI-0.05\%-0.025\%) was measured $338 \pm 19 \mathrm{~nm}$, exhibiting a Young's modulus of the nanofilm $3.57 \pm 0.60 \mathrm{GPa}$. This is somewhat higher than the mechanical strength we reported earlier for nanofilms created on a sacrificial layer, ${ }^{[1]}$ and we note that this calculation is highly sensitive to nanofilm thickness.
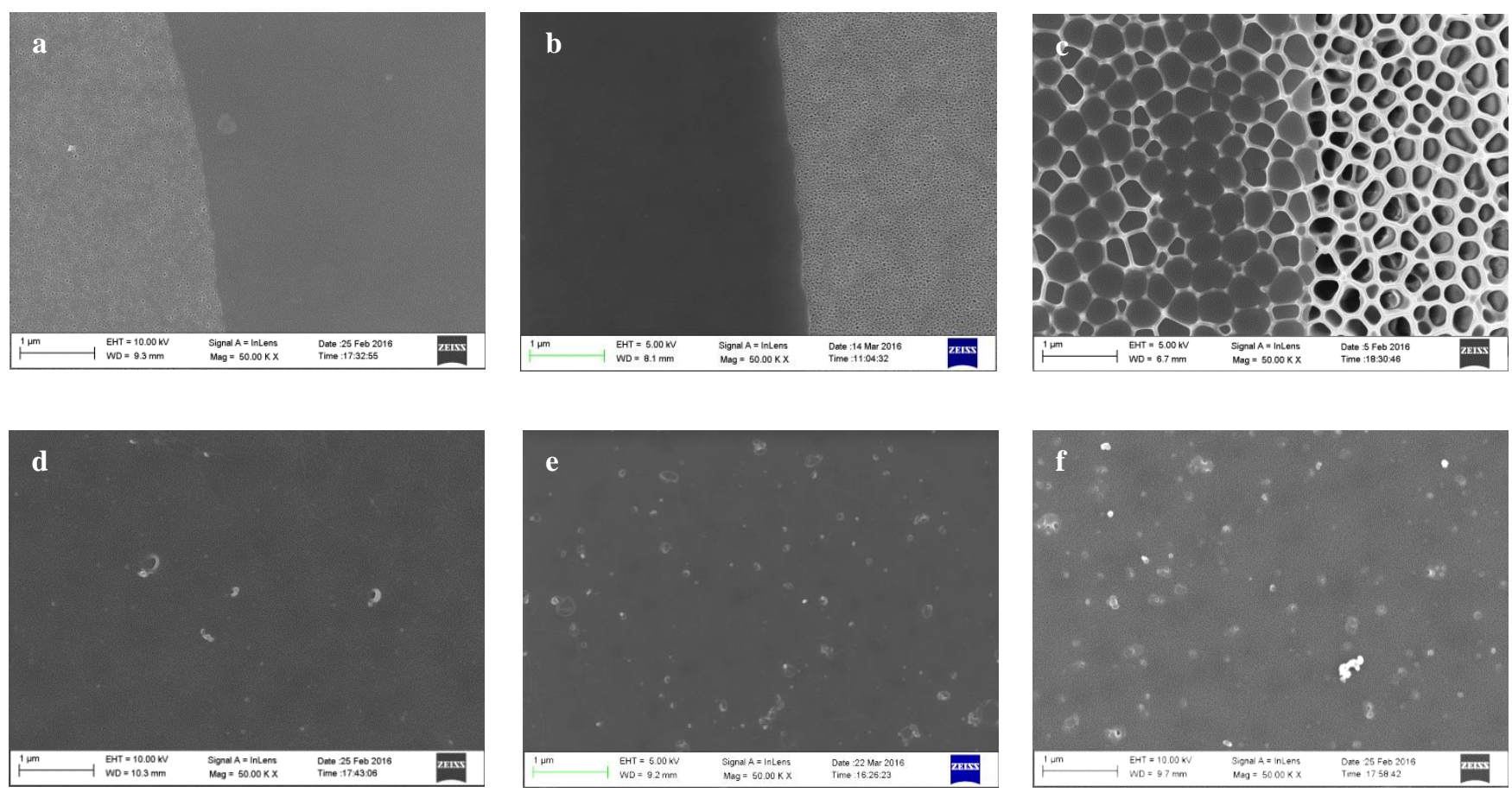

Figure S8. SEM surface images of nanofilms made with various monomer concentrations reacted for $1 \mathrm{~min}$ at the free aqueous-organic interface. a) $\mathrm{C}_{\mathrm{MPD}}: \mathrm{C}_{\mathrm{TMC}}$ (mass concentration ratio of MPD and TMC) $=0.01: 0.005$. b) $\mathrm{C}_{\mathrm{MPD}}: \mathrm{C}_{\mathrm{TMC}}=0.05: 0.025$. c) $\mathrm{C}_{\mathrm{MPD}}: \mathrm{C}_{\mathrm{TMC}}=0.1: 0.05$. d) $\mathrm{C}_{\mathrm{MPD}}: \mathrm{C}_{\mathrm{TMC}}=0.2: 0.1$. e) $\mathrm{C}_{\mathrm{MPD}}: \mathrm{C}_{\mathrm{TMC}}=1: 0.05$. f) $\mathrm{C}_{\mathrm{MPD}}: \mathrm{C}_{\mathrm{TMC}}=2: 0.1$. (a-c) nanofilms were transferred onto alumina supports, and (d-f) nanofilms were transferred onto polysulfone supports. 
WILEY-VCH
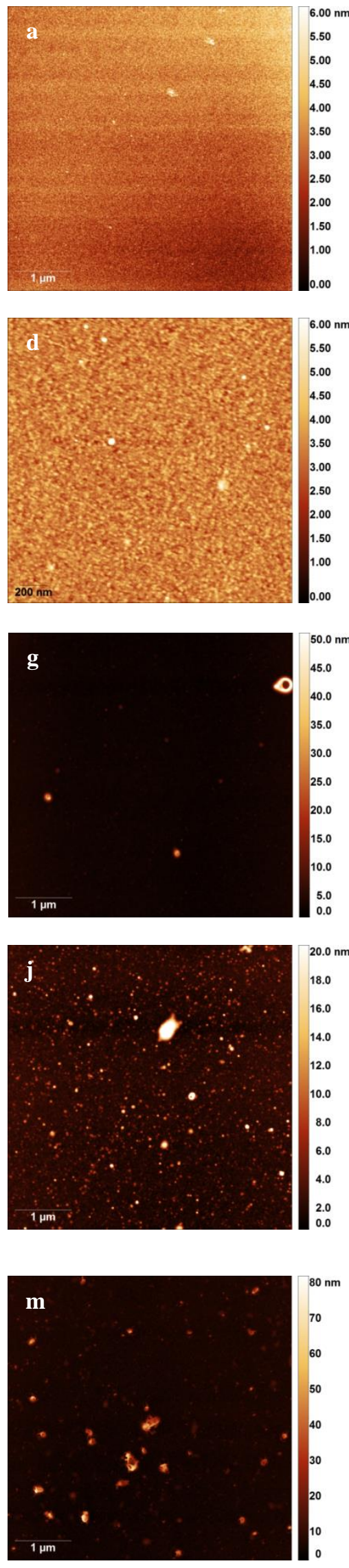
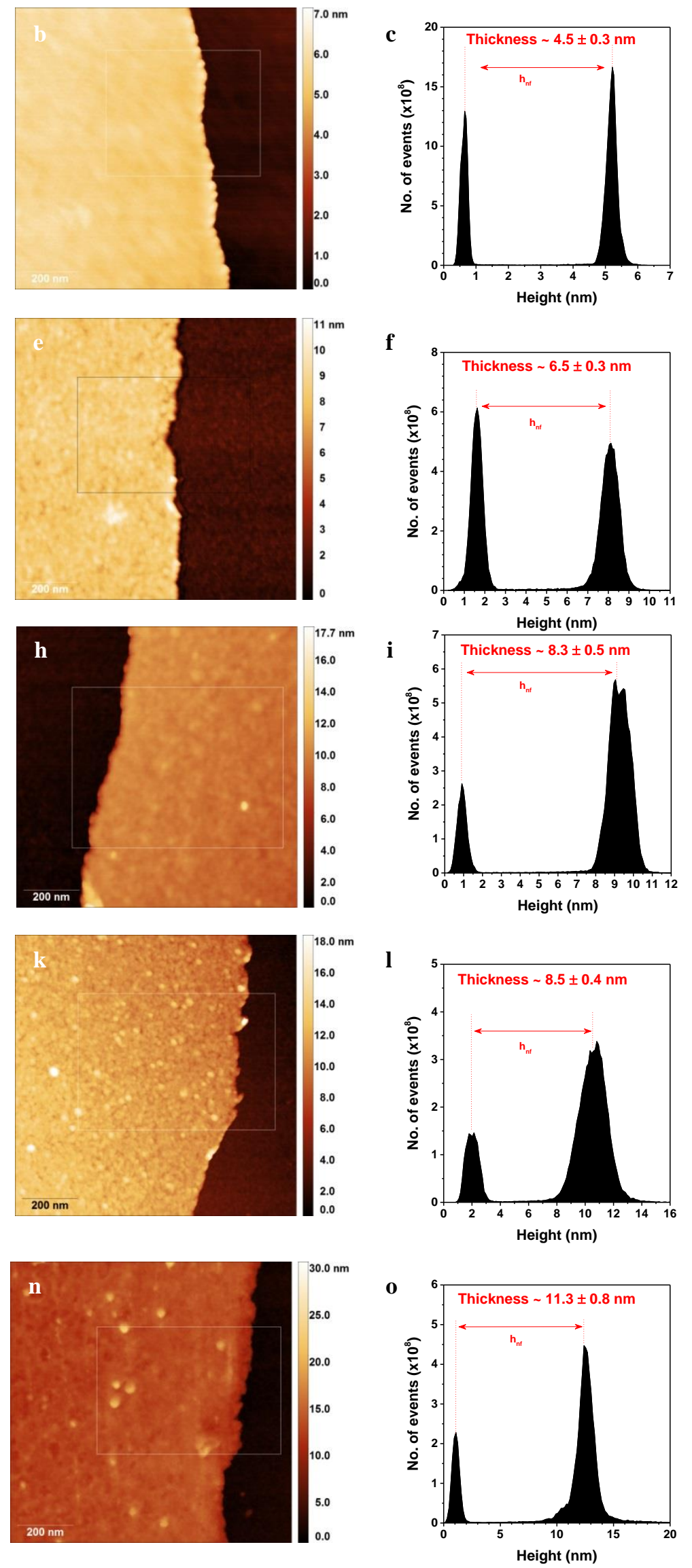

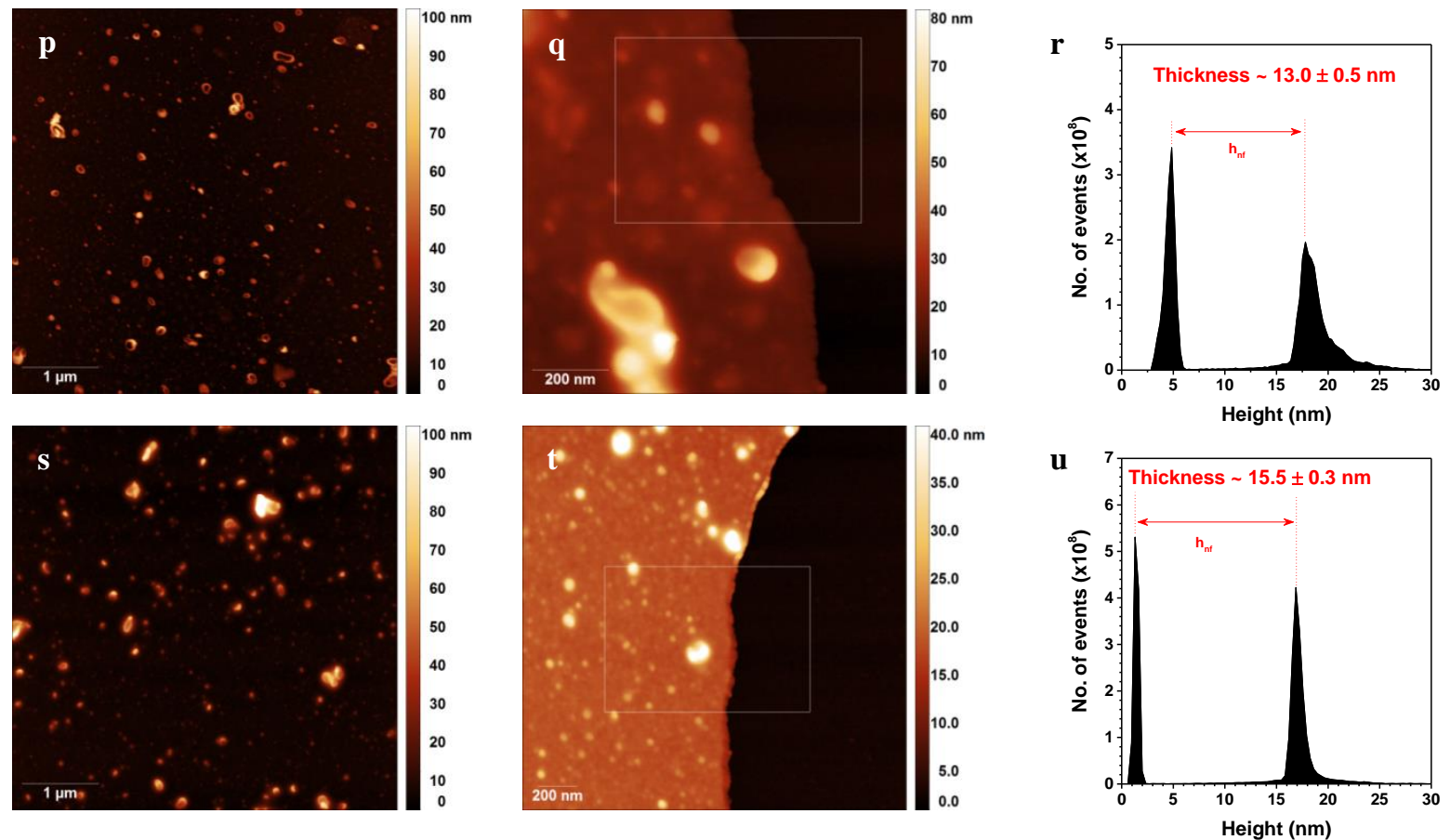

Figure S9. AFM height images and profiles for nanofilms made under controlled conditions at a free aqueous-organic interface followed by transfer onto silicon wafers. a-c) $\mathrm{C}_{\mathrm{MPD}}: \mathrm{C}_{\mathrm{TMC}}$ $=0.01: 0.005$. d-f) $\mathrm{C}_{\mathrm{MPD}}: \mathrm{C}_{\mathrm{TMC}}=0.05: 0.025$. g-i) $\mathrm{C}_{\mathrm{MPD}}: \mathrm{C}_{\mathrm{TMC}}=0.1: 0.05$. j-1) $\mathrm{C}_{\mathrm{MPD}}: \mathrm{C}_{\mathrm{TMC}}=$ 0.2:0.1. m-o) $\left.\left.\mathrm{C}_{\mathrm{MPD}}: \mathrm{C}_{\mathrm{TMC}}=1: 0.05 . \mathrm{p}-\mathrm{r}\right) \mathrm{C}_{\mathrm{MPD}}: \mathrm{C}_{\mathrm{TMC}}=2: 0.1 . \mathrm{s}-\mathrm{u}\right) \mathrm{C}_{\mathrm{MPD}}: \mathrm{C}_{\mathrm{TMC}}=3: 0.15 . \mathrm{h}_{\mathrm{nf}}$ denotes the thickness of the nanofilm.
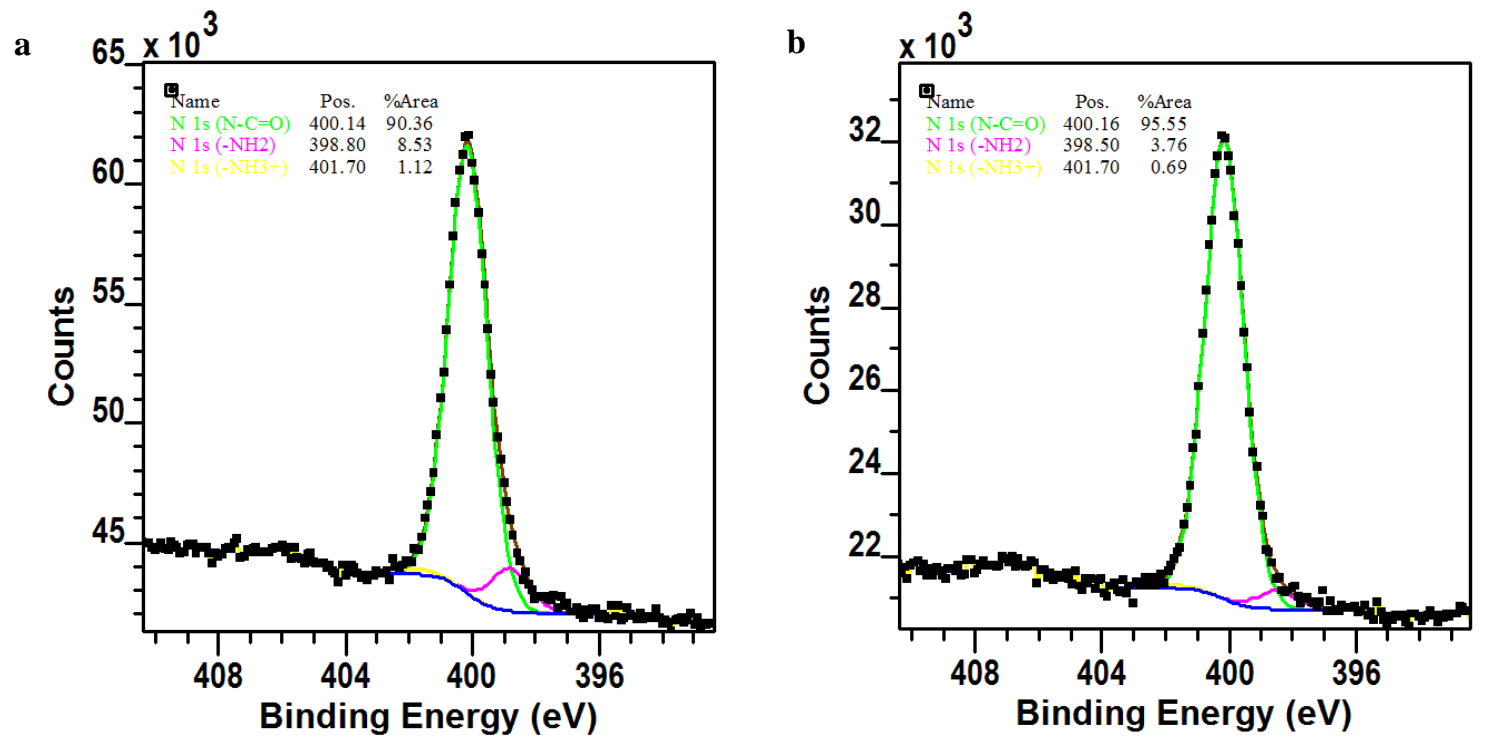

Figure S10. N1s narrow scan spectra and the deconvolution spectra for the nanofilms (IP@FI-3\%-0.15\%). a) from the front surface and b) from the rear surface. 
$\mathbf{a}$

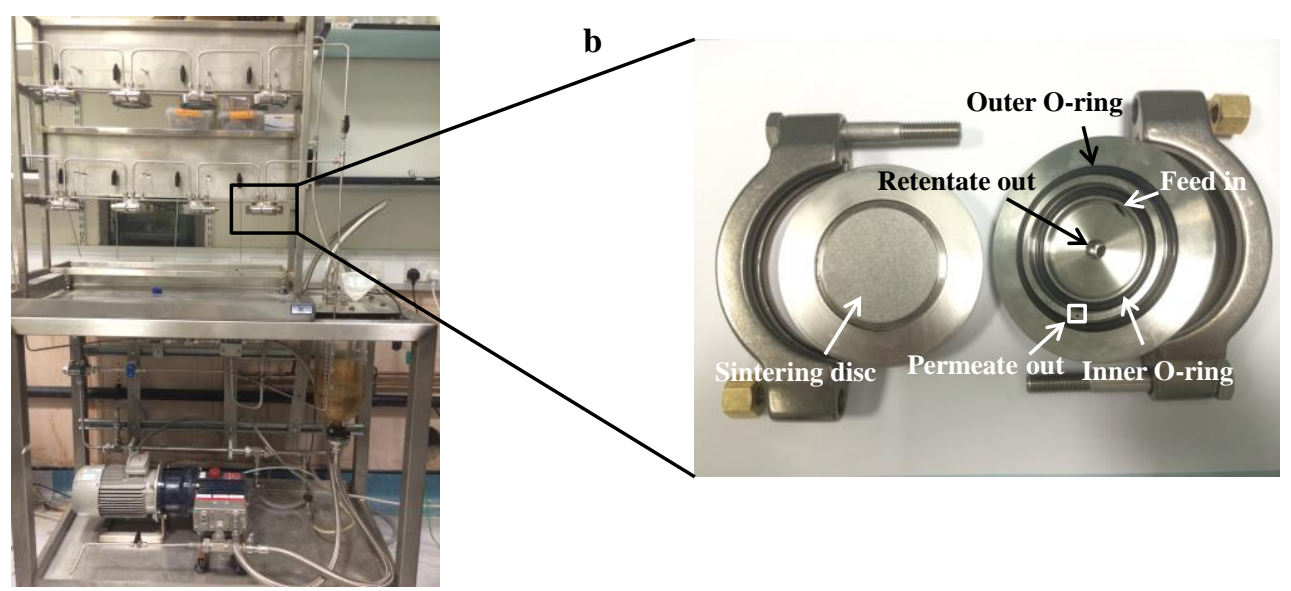

Figure S11. Photograph of a) the crossflow rig containing 8 cells (4 cells in two parallel rows) for desalination testing and $b$ ) the filtration cell for mounting the nanofilm composite membranes.

Table S2. Performance of composite membranes comprising polyamide nanofilms fabricated at a free aqueous-organic interface and transferred onto various supports.

\begin{tabular}{|c|c|c|c|c|c|}
\hline $\begin{array}{l}\text { Nanofilms made at the free interface and } \\
\text { transferred onto supports (FI)* } \\
\text { (IP@FI-MPD wt \%-TMC wt } \% \text {-support) }\end{array}$ & $\begin{array}{l}\text { MPD } \\
\text { concentration } \\
(w t \%)\end{array}$ & $\begin{array}{l}\text { TMC } \\
\text { concentration } \\
(w t \%)\end{array}$ & Support $^{\ddagger}$ & $\begin{array}{l}\text { Water } \\
\text { permeance }^{\S} \\
\left(\mathbf{L} \cdot \mathbf{m}^{-2} \cdot \mathbf{h}^{-1} \cdot \text { bar }^{-1}\right)\end{array}$ & $\begin{array}{l}\mathrm{NaCl} \\
\text { rejection }^{\S} \\
(\%)\end{array}$ \\
\hline IP@FI-0.05\%-0.025\%-PTFE & 0.05 & 0.025 & PTFE & $4.06 \pm 0.18$ & $93.3 \pm 0.8$ \\
\hline IP@FI-0.05\%-0.025\%-Psf & 0.05 & 0.025 & Polysulfone & $2.69 \pm 0.07$ & $96.0 \pm 1.9$ \\
\hline IP@FI-0.06\%-0.03\%-Psf & 0.06 & 0.03 & Polysulfone & $2.50 \pm 0.03$ & $92.7 \pm 0.6$ \\
\hline IP@ FI-0.1\%-0.05\%-Psf & 0.1 & 0.05 & Polysulfone & $1.58 \pm 0.11$ & $94.5 \pm 0.4$ \\
\hline IP@FI-0.2\%-0.1\%-Psf & 0.2 & 0.1 & Polysulfone & $1.55 \pm 0.14$ & $95.4 \pm 2.8$ \\
\hline IP@FI-1\%-0.05\%-Psf & 1 & 0.05 & Polysulfone & $1.20 \pm 0.05$ & $98.4 \pm 1.1$ \\
\hline IP@FI-2\%-0.1\%-Psf & 2 & 0.1 & Polysulfone & $0.99 \pm 0.05$ & $93.2 \pm 4.0$ \\
\hline IP@FI-3\%-0.15\%-Psf & 3 & 0.15 & Polysulfone & $0.75 \pm 0.05$ & $95.5 \pm 4.1$ \\
\hline IP@ FI-3\%-0.15\% -Psf-flipped ${ }^{\dagger}$ & 3 & 0.15 & Polysulfone & $0.67 \pm 0.05$ & $95.0 \pm 1.5$ \\
\hline IP@FI-3\%-0.15\%-XP84 & 3 & 0.15 & XP84 & $0.32 \pm 0.01$ & $97.9 \pm 1.1$ \\
\hline IP@FI-3\%-0.15\%-XPEI & 3 & 0.15 & XPEI & $0.55 \pm 0.02$ & $94.6 \pm 2.0$ \\
\hline IP@FI-3\%-0.15\%-PTFE & 3 & 0.15 & PTFE & $1.49 \pm 0.11$ & $95.3 \pm 1.5$ \\
\hline
\end{tabular}

"The reaction time for all nanofilms was 1 minute. ${ }^{\dagger}$ Nanofilms were flipped over with the rear (aqueous facing) surface in contact with the feed and the front (hexane facing) surface attached to the support. "Supports include crosslinked polyimide (XP84), crosslinked polyetherimide (XPEI), polysulfone (Psf), and hydrophilic polytetrafluoroethylene (PTFE). ${ }^{8}$ Water permeance and $\mathrm{NaCl}$ rejection were measured in a cross-flow rig at $30{ }^{\circ} \mathrm{C}$ under 20 bar with $2 \mathrm{~g} . \mathrm{L}^{-1} \mathrm{NaCl}$ solution as the feed. $\mathrm{L} \cdot \mathrm{m}^{-2} \cdot \mathrm{h}^{-1}$.bar ${ }^{-1}$ stands for liter per square meter per hour per bar. 


\section{WILEY-VCH}
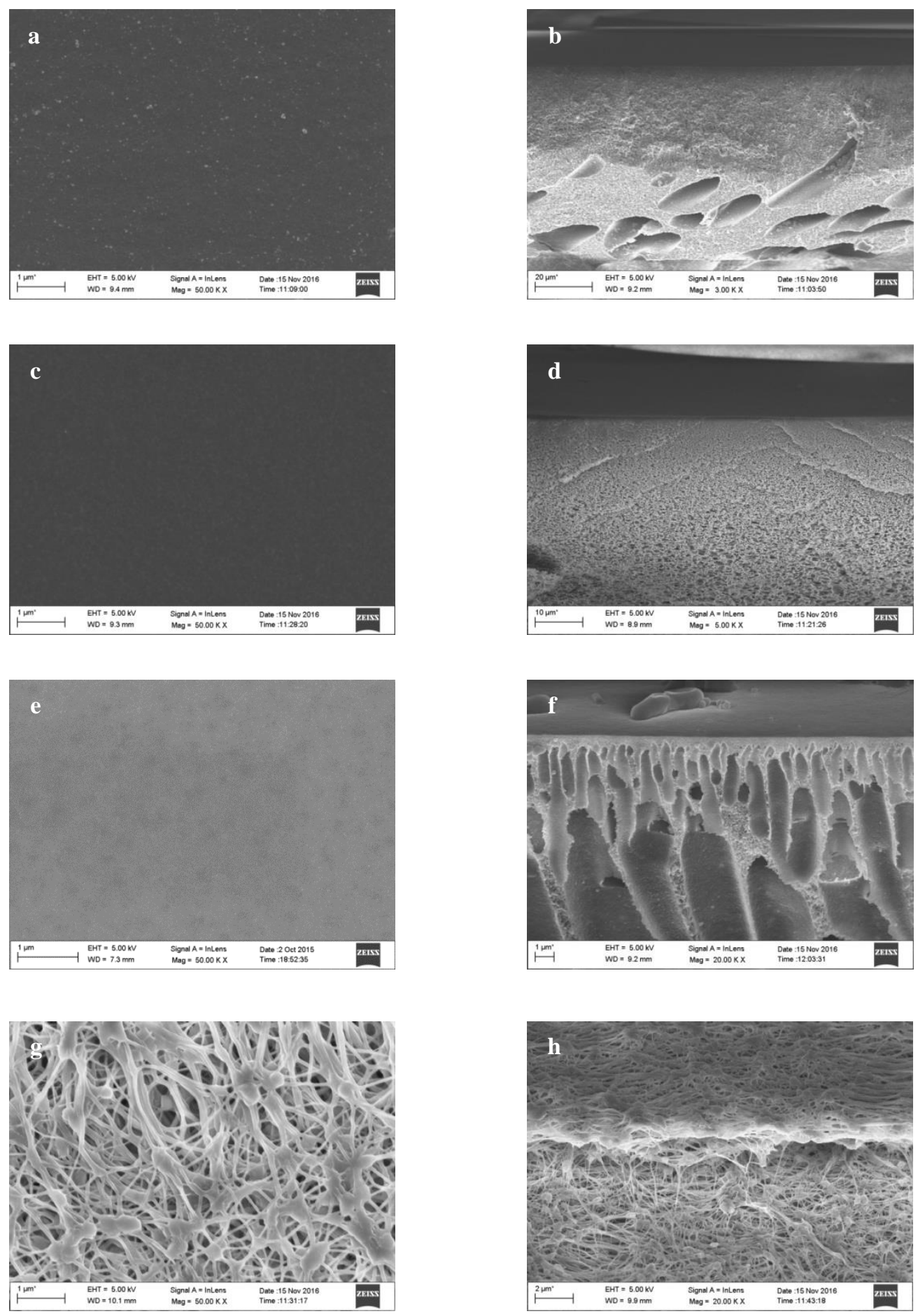

Figure S12. Surface and cross-sectional SEM images of support membranes. a and b) XP84 supports. $\mathrm{c}$ and d) XPEI supports. e and f) Polysulfone supports. $g$ and h) Hydrophilic PTFE supports. 
WILEY-VCH

Table S3. Ratio of support permeance to nanofilm composite membrane permeance.

\begin{tabular}{|c|c|c|c|c|}
\hline $\begin{array}{l}\text { Polyamide nanofilms made at the free } \\
\text { interface (IP@FI) or by conventional } \\
\text { interfacial polymerization (IP) } \\
\text { (Method-MPD wt\%-TMC wt \%-support) }\end{array}$ & Support & $\begin{array}{l}\text { Pure water permeance of } \\
\text { support membranes, } \\
\text { P }_{\text {support }} \\
\left(\text { L.m }{ }^{-2} \cdot h^{-1} \cdot \text { bar }^{-1}\right)\end{array}$ & $\begin{array}{l}\text { Water permeance of } \\
\text { nanofilm composite } \\
\text { membranes, } \mathrm{P}_{\mathrm{NFC}} \\
\left(\mathrm{L} \cdot \mathrm{m}^{-2} \cdot \mathrm{h}^{-1} \cdot \mathrm{bar}^{-1}\right)\end{array}$ & $\begin{array}{l}\text { Permeance } \\
\text { ratio, } \\
\mathbf{P}_{\text {support }} / \mathbf{P}_{\mathrm{NFC}}\end{array}$ \\
\hline IP@FI-3\%-0.15\%-XP84 & XP84 & $106 \pm 8$ & $0.32 \pm 0.01$ & 330 \\
\hline IP@FI-3\%-0.15\%-XPEI & XPEI & $125 \pm 6$ & $0.55 \pm 0.02$ & 230 \\
\hline IP@FI-3\%-0.15\%-Psf & Polysulfone & $256 \pm 9$ & $0.75 \pm 0.05$ & 340 \\
\hline IP@FI-3\%-0.15\%-PTFE & PTFE & $407 \pm 10$ & $1.49 \pm 0.11$ & 270 \\
\hline IP-2\%-0.1\%-Psf ${ }^{\dagger}$ & Polysulfone & $256 \pm 9$ & $2.90 \pm 0.20$ & 88 \\
\hline
\end{tabular}

${ }^{*}$ The pure water permeance of the support was measured in a crossflow rig at $30{ }^{\circ} \mathrm{C}$ under 1 bar. L.m ${ }^{-2} \cdot \mathrm{h}^{-1} \cdot$ bar $^{-1}$ stands for liter per square meter per hour per bar. 'The membrane was made via conventional interfacial polymerization process on a polysulfone support membrane, for which the membrane surface appears crumpled as shown in Figure S3a.

If a simple resistances-in-series model applies to the water transport through the nanofilm composite membranes, the permeance (normalized by pressure) of nanofilm composite membranes, $P_{N F C}$, should follow Equation $\mathrm{S} 4$. For the pristine support membrane $i$, the pure water permeance, $P_{\text {support }, i}$, can be expressed as Equation S4.

$$
\begin{aligned}
& P_{N F C}=\frac{1}{R_{\text {nanofilm }}+R_{\text {support }, i}} \\
& P_{\text {support }, i}=\frac{1}{R_{\text {support }, i}}
\end{aligned}
$$

where $R_{\text {nanofilm }}$ is the resistance of the polyamide nanofilms, $R_{\text {support }, i}$ is the resistance of the support membrane $i$.

The usual assumption is that the resistance of support membranes is negligible. If so, Equation S4 can be simplified as Equation S6.

$$
P_{N F C} \approx \frac{1}{R_{\text {nanofilm }}}
$$




\section{WILEY-VCH}

In Table S3, the permeance of composite membranes comprising nanofilms transferred onto XP84 support (IP@FI-3\%-0.15\%-XP84) was $0.32 \mathrm{~L} \cdot \mathrm{m}^{-2} \cdot \mathrm{h}^{-1} \cdot \mathrm{bar}^{-1}$. According to Equation S6, the resistance of nanofilm can be calculated as:

$R_{\text {nanofilm }} \approx \frac{1}{P_{N F C}(I P @ F I-3 \%-0.15 \%-X P 84)}=3125 \mathrm{~h} \cdot \mathrm{bar} . \mathrm{m}^{-1}$

Equation S7

For the polysulfone support membrane, the resistance can be calculated from Equation S5 by giving the support permeance as $256 \mathrm{~L} \cdot \mathrm{m}^{-2} \cdot \mathrm{h}^{-1} \cdot \mathrm{bar}^{-1}$ (Table S3).

$R_{\text {support }, P s f}=\frac{1}{P_{\text {support }, P s f}}=3.9$ h.bar. $m^{-1}$

Equation S8

Since the nanofilms were made under identical conditions at the free aqueous-organic interface, their resistance will be the same when they are transferred onto polysulfone support. By substituting resistances of the nanofilm and the polysulfone support membrane from Equation S7 and S8 into Equation S4, the permeance of nanofilm composite membrane on the polysulfone support (IP@FI-3\%-0.15\%-Psf) can be obtained as:

$P_{N F C}(I P @ F I-3 \%-0.15 \%-P s f)=\frac{1}{R_{\text {nanofilm }}+R_{\text {support }, \text { Psf }}}=0.32 L \cdot \mathrm{m}^{-2} \cdot \mathrm{h}^{-1} \cdot$ bar $^{-1}$

This remains the same as composite membranes comprising nanofilms are transferred onto the XP84 support (IP@FI-3\%-0.15\%-XP84). However, as shown in Table S3, the experimentally measured permeance for nanofilms transferred onto the polysulfone support (IP@FI-3\%-0.15\%-Psf) was $0.75 \mathrm{~L} \cdot \mathrm{m}^{-2} \cdot \mathrm{h}^{-1} \cdot \mathrm{bar}^{-1}$, more than double the calculated value from the model. Therefore, the assumption that the support resistance is negligible is not valid. In fact, the support membrane and permeance significantly affect the overall permeance of nanofilm composite membranes. 


\section{WILEY-VCH}

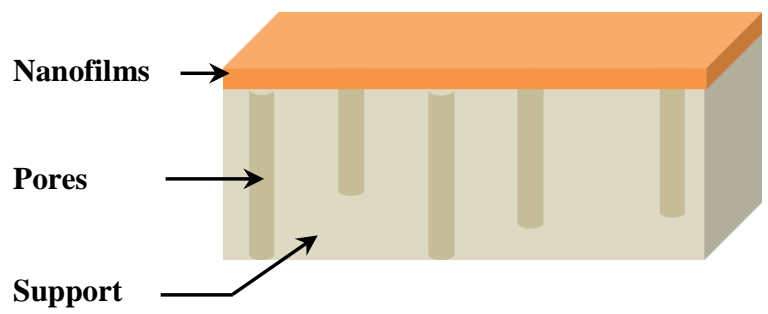

c

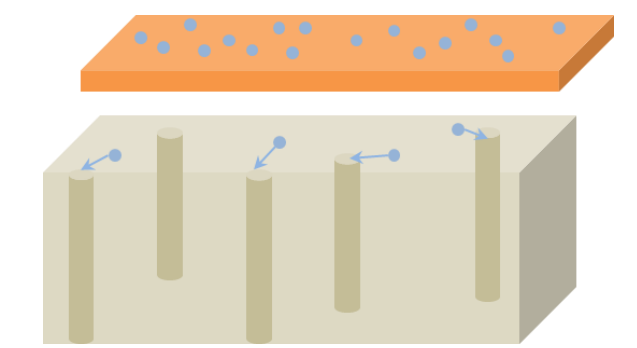

b

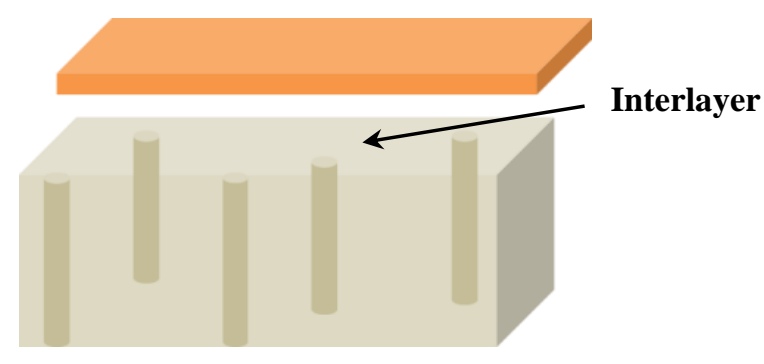

d

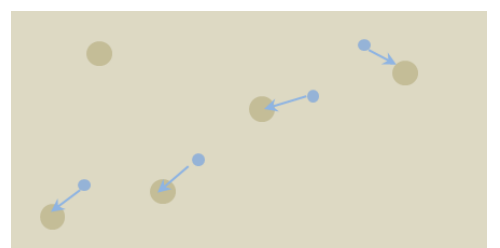

= water molecules

$\longrightarrow=$ direction of sliding flow

Figure S13. Schematic of postulated sliding flow effect for water molecules in the interlayer between the nanofilm and the support. a) Nanofilm composite membranes comprising dense polyamide nanofilms on supports with pore sizes ranging from $\sim 10$ to $200 \mathrm{~nm}$. b) Interlayer between the nanofilm and the support. c) Water molecules transport through composite membranes, after which they travel lateral distances to the closet pores on the support for further filtration. d) Top view of c.

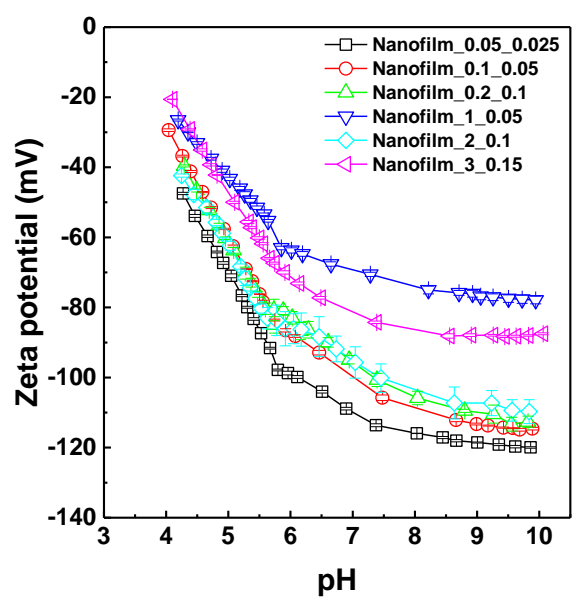

Figure S14. Zeta potential of polyamide nanofilms fabricated from different monomer concentrations at a free aqueous-organic interface. 

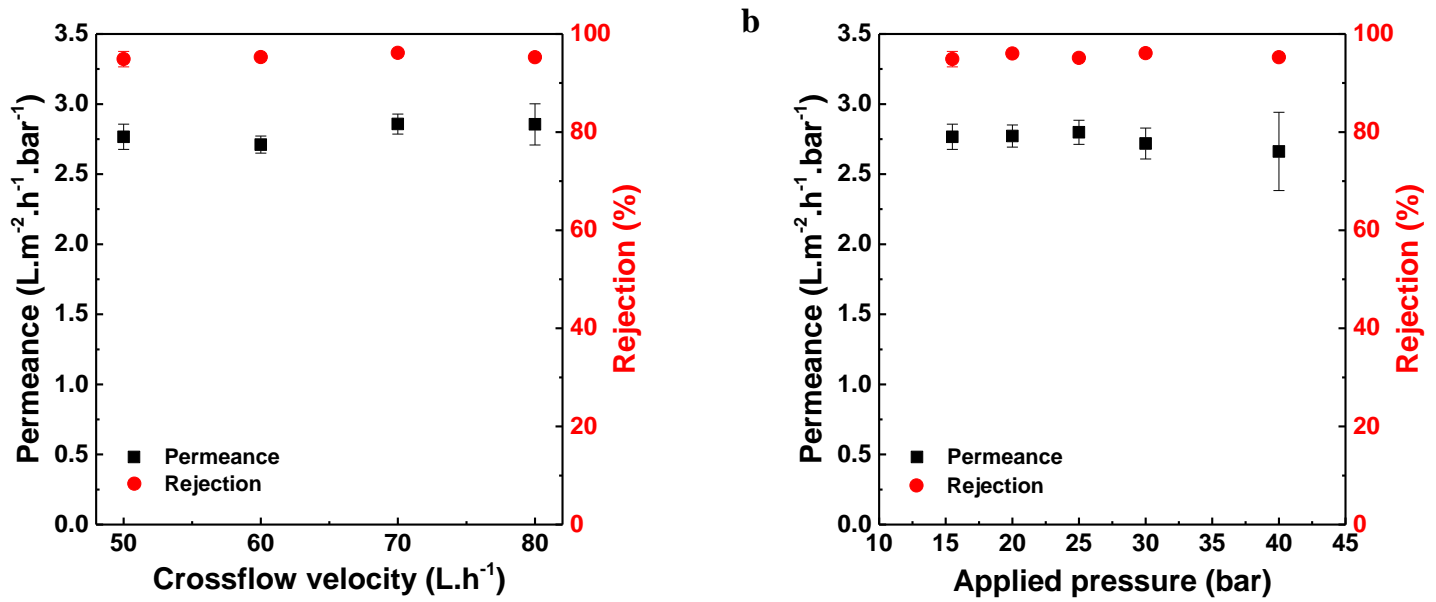

Figure S15. Performance of composite membranes comprising $\sim 6.5 \mathrm{~nm}$ nanofilms on polysulfone supports at different operating conditions. a) increasing crossflow velocities per row of membrane cells and b) increasing applied pressures. All data in a) were collected in a crossflow rig under 15.5 bar with 2 g. $\mathrm{L}^{-1} \mathrm{NaCl}$ feed solution at a recovery of $15 \%$. All data in b) were collected in a crossflow rig with $50 \mathrm{~L} \cdot \mathrm{h}^{-1}$ per row of membrane cells with 2 g.L $\mathrm{L}^{-1}$ $\mathrm{NaCl}$ feed solution at a recovery of $15 \%$.

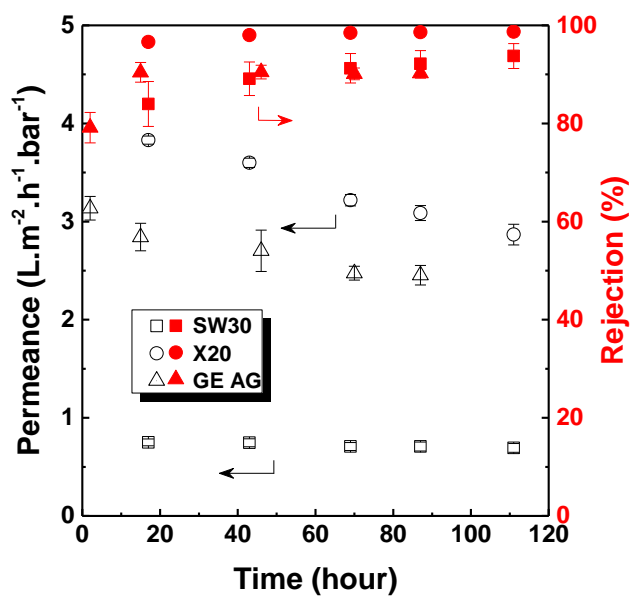

Figure S16. Permeance and $\mathrm{NaCl}$ rejection of commercial $\mathrm{RO}$ membrane (SW30) and brackish water membranes (X20 and GE AG) determined in this work. Operating conditions are listed in Table S4. 
Table S4. Performance of commercial RO and brackish water membranes. All experiments involving Dow Filmtec ${ }^{\mathrm{TM}}$ BW30 were conducted in the laboratories of the referenced researchers.

\begin{tabular}{|c|c|c|c|c|c|}
\hline $\begin{array}{l}\text { Membrane } \\
\text { type }\end{array}$ & $\begin{array}{l}\text { Operating } \\
\text { pressure (bar) }\end{array}$ & $\begin{array}{l}\mathrm{NaCl} \text { concentration } \\
\left(\mathrm{g} . \mathrm{L}^{-1}\right)\end{array}$ & $\begin{array}{l}\text { Permeance } \\
\left(\mathrm{L} \cdot \mathrm{m}^{-2} \cdot \mathrm{h}^{-1} \cdot \mathrm{bar}^{-1}\right)\end{array}$ & $\begin{array}{l}\text { Rejection } \\
(\%)\end{array}$ & Ref. \\
\hline BW30 & 5 & 0.5 & 3.6 & 93.5 & 2 \\
\hline BW30 & 15.5 (225 psi) & 1.5 & 2.71 & 94.8 & 3 \\
\hline BW30 & 10 & 0.5 & 2.5 & 95.0 & 4 \\
\hline BW30 & 5 & $0.585(10 \mathrm{mM})$ & 2.7 & 96.0 & 5 \\
\hline BW30 & 8 & 2 & $2.8^{*}$ & 96.9 & 6 \\
\hline BW30 & 13.8 & $0.585(10 \mathrm{mM})$ & $3.96 *$ & 97.9 & 7 \\
\hline BW30 & 15.5 & 2 & 2.15 & 98.6 & 8 \\
\hline BW30 & 15.5 & 2 & 3.47 & 98.8 & 9 \\
\hline BW30 & 15 & 2 & 3.33 & 99.2 & 10 \\
\hline SW30 & 20 & 2 & 0.70 & 93.8 & $\begin{array}{l}\text { Tested in } \\
\text { our lab }\end{array}$ \\
\hline $\mathrm{X} 20^{\dagger}$ & 20 & 2 & 2.87 & 98.7 & $\begin{array}{l}\text { Tested in } \\
\text { our lab }\end{array}$ \\
\hline GE AG & 20 & 2 & 2.45 & 90.2 & $\begin{array}{l}\text { Tested in } \\
\text { our lab }\end{array}$ \\
\hline
\end{tabular}

*Data were collected for pure water. $\dagger$ X20 is based on polyamide-urea chemistry while all other membranes are based on polyamide chemistry. 


\section{WILEY-VCH}

\section{Reference}

[1] S. Karan, Z. W. Jiang, A. G. Livingston, Science 2015, 348, 1347.

[2] X. S. Li, S. R. Chou, R. Wang, L. Shi, W. X. Fang, G. Chaitra, C. Y. Y. Tang, J. Torres, X. Hu, A. G. Fane, J Membrane Sci 2015, 494, 68.

[3] S. Belfer, Y. Purinson, R. Fainshtein, Y. Radchenko, O. Kedem, J Membrane Sci 1998, $139,175$.

[4] X. X. Song, S. R. Qi, C. Y. Y. Tang, C. J. Gao, J Membrane Sci 2017, 540, 10.

[5] Y. Zhao, C. Q. Qiu, X. S. Li, A. Vararattanavech, W. M. Shen, J. Torres, C. HelixNielsen, R. Wang, X. Hu, A. G. Fane, C. Y. Tang, J Membrane Sci 2012, 423, 422.

[6] A. Antony, A. Branch, G. Leslie, P. Le-Clech, J Membrane Sci 2016, 520, 37.

[7] C. Y. Y. Tang, Y. N. Kwon, J. O. Leckie, Desalination 2009, 242, 168.

[8] J. T. Duan, Y. C. Pan, F. Pacheco, E. Litwiller, Z. P. Lai, I. Pinnau, J Membrane Sci 2015, 476, 303.

[9] W. Choi, S. Jeon, S. J. Kwon, H. Park, Y. I. Park, S. E. Nam, P. S. Lee, J. S. Lee, J. Choi, S. Hong, E. P. Chan, J. H. Lee, J Membrane Sci 2017, 527, 121.

[10] H. Yan, X. P. Miao, J. Xu, G. Y. Pan, Y. Zhang, Y. T. Shi, M. Guo, Y. Q. Liu, J. Membrane Sci. 2015, 475, 504. 